PERCEPTIVE DEAFNESS FOR LOW TONES

By

TOSHIThaA IINUMA, T TTSUYA SHITARA, RYoHo UEDA

TOMOYON HOSHINO, KENנ: NAKAMURA and ICH1RO KIRIKAE

From the Department of Otorhinolaryngology, Faculty of Medicine,

University of Tokyo. (Director; Prof. 1. Kirikat)

In an attempt to locate lesions in the auditory system, the author examined 46 cases of perceptive low tone deafness by various methods of hearing and vestibular function tests. Forty-one cases were bilaterally involved and five unilaterally.

Hearing was eatimated by performing the conventional air and bone conduction tests, recrujtment test, temporaly threshold shift test using a Békésy type audioneter, distorted speech perception test with use of $1290 \mathrm{cps}$ low pass and $1700 \mathrm{cps}$ high pass filters, and binaural hearing test using an interchannel time difference (ITD) apparatus. The vestibular function was also examined by observing spontaneous, pasitional and positioning nystagmue and by the caloric test and the optoki. netic pattesn tests. Differentiation between the peripheral and the retrolabyrinthine lesions was anticipated from the results.

It was concluded that the lesion in the patient of perceptive low tone deafness was peripherai, retrolabyrinthine or both, suggesting a syatemic disease in the auditory system.

\title{
低音性感音性難聴に関する研究
}

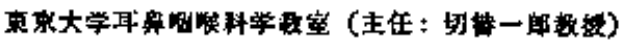

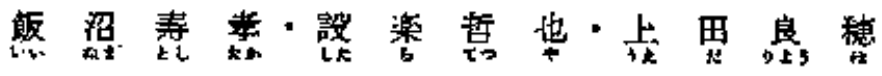

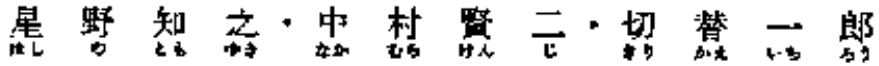 \\ 目次 \\ 1. 贯

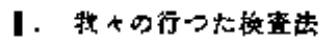

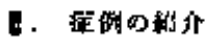

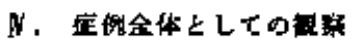

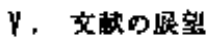 \\ ท. 孝接 \\ ท. 拮船 \\ 女

\section{I. 样}

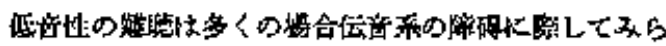

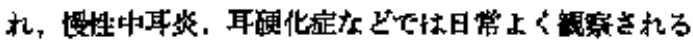

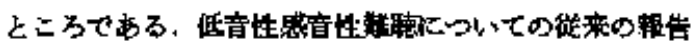

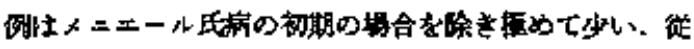

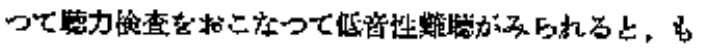

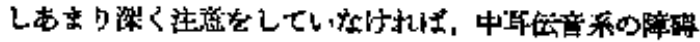

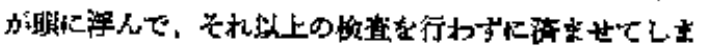

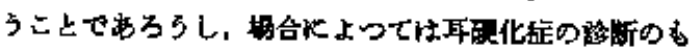

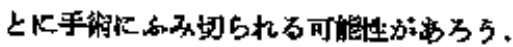

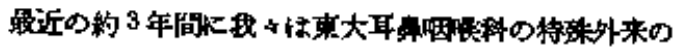

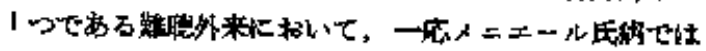

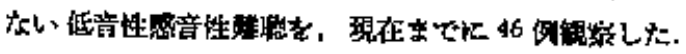

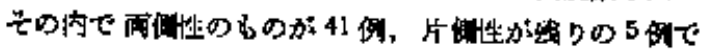

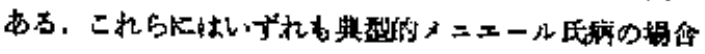

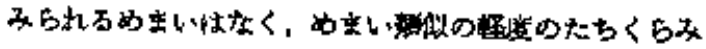

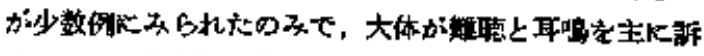

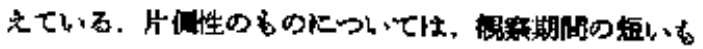

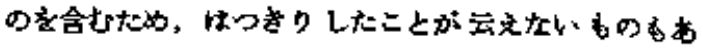




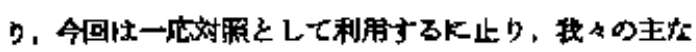

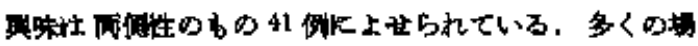

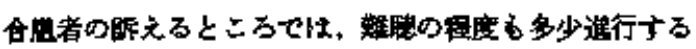

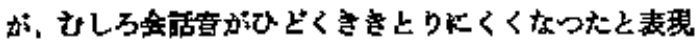

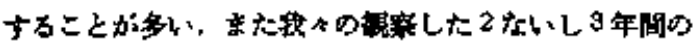

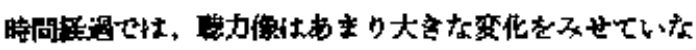

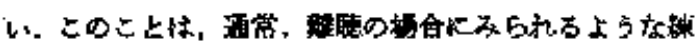

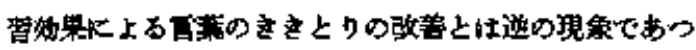

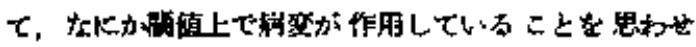

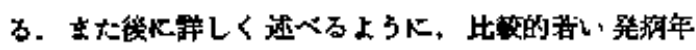

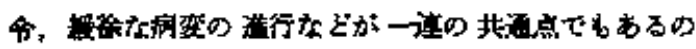

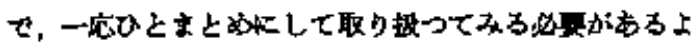

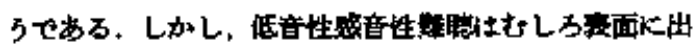

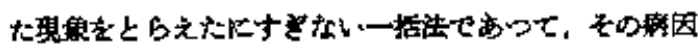

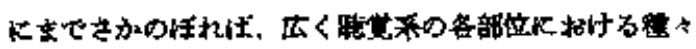

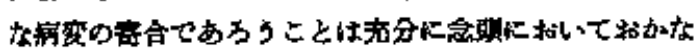

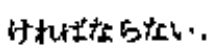

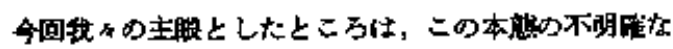

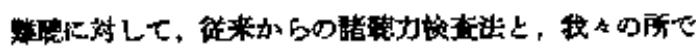

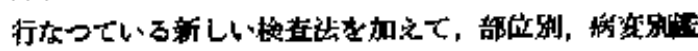

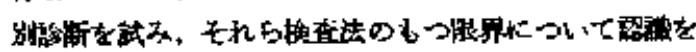

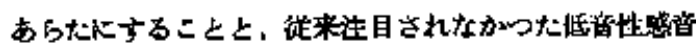

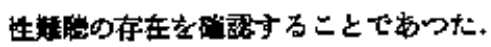

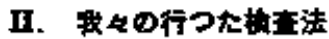

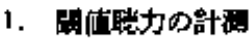

我々仕 シオン、オージオィーター Model A-1002D

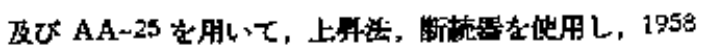

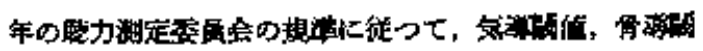

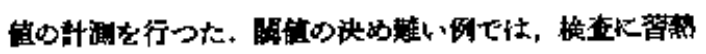

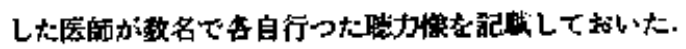

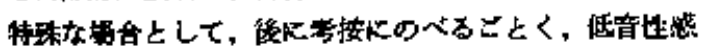

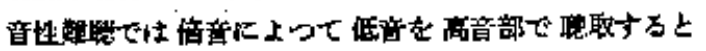

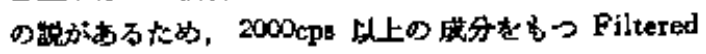

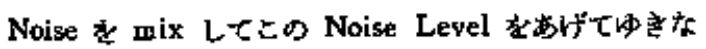

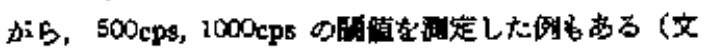
触 1 ).

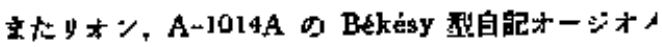

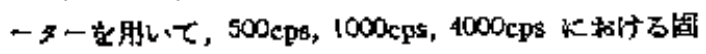

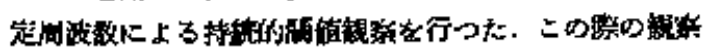

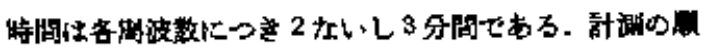

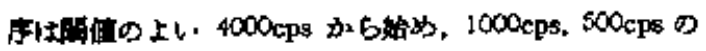

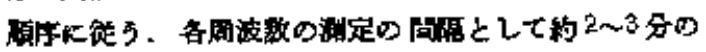

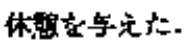

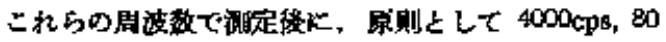

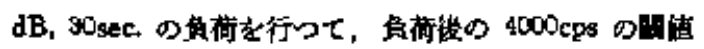

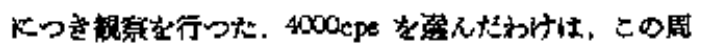

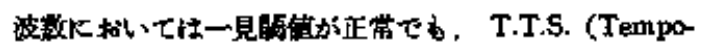
raly Threshold Shift) が多〈みられたり，总荷媵の

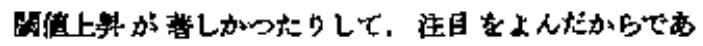

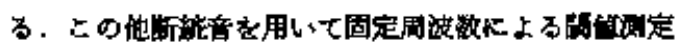

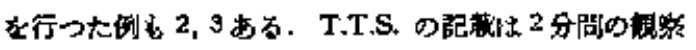

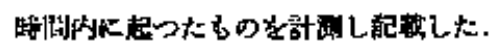

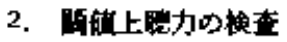

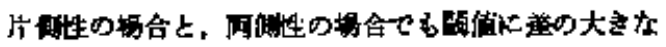
堵合仕 Balsnce Test 光用いて Recruitmentをしらべ t心. MCL Test, DL Tert, Noise Test 壮行らていな w.

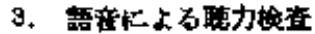

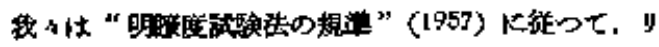
オン整 Speech Sound Generator AP-1017 t用い,

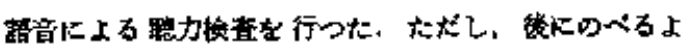

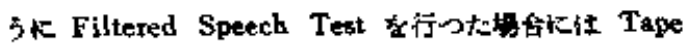

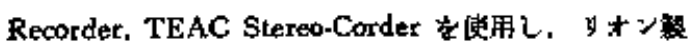

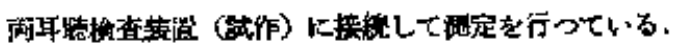

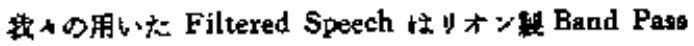

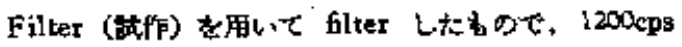
Low Pass と $1700 \mathrm{cps}$ High Pass とであり, 1200cpa

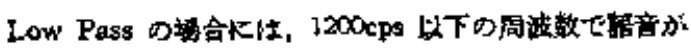
聴取され、1700 cps High Pass では, 1700 cps 以上の

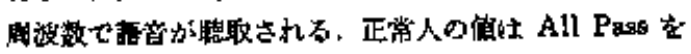

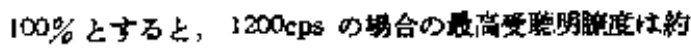
50\%，1700 cps の场台哬 70\%でる. この Filtered

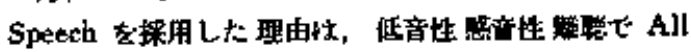

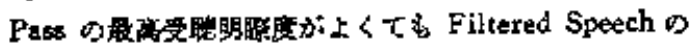

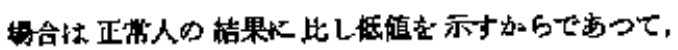

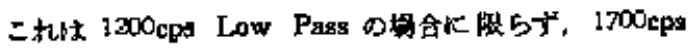

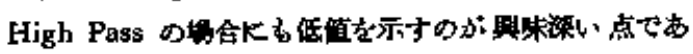
万5.

4. 两耳方南感の椟查

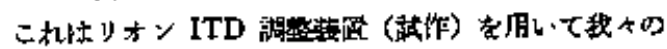

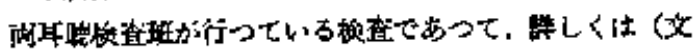

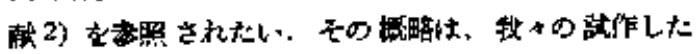
ITD (Isterchannel Time Difference)

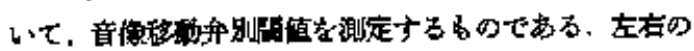

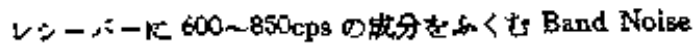

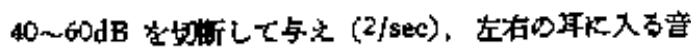




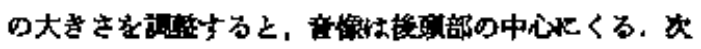

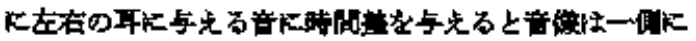

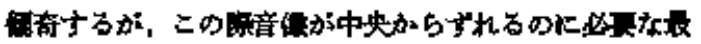

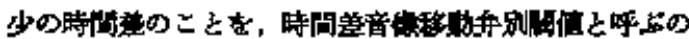
でるる。

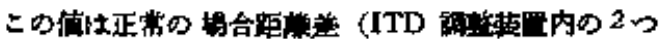

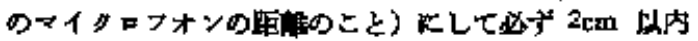

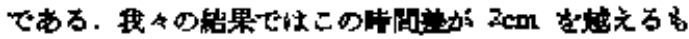

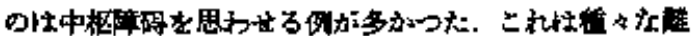

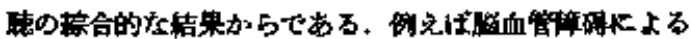

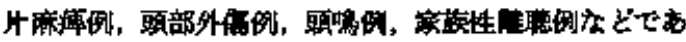

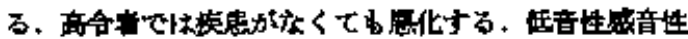

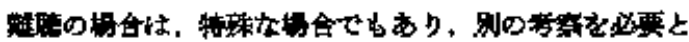

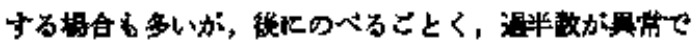
あつたことは注目すべきである。

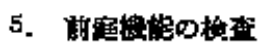

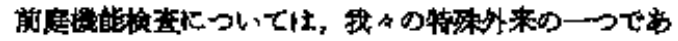

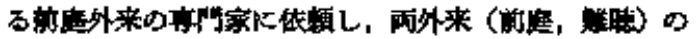

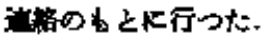

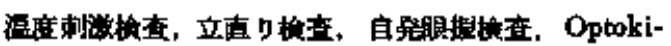

\section{水○え16才令}

1. オージオグラム

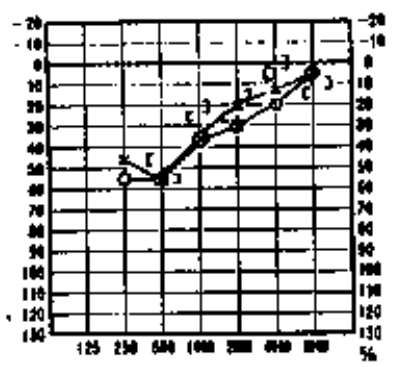

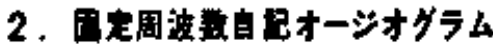

\begin{tabular}{|c|c|c|}
\hline & 豆 & T. T. 8 \\
\hline \multirow{2}{*}{$4 \mathrm{kC}$} & 5 & 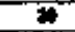 \\
\hline & $\overline{\mathbf{6}}$ & $=$ \\
\hline \multirow{2}{*}{$\operatorname{lnc} \frac{\pi}{t}$} & 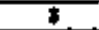 & 20 \\
\hline & 4 & 12 \\
\hline I & 2 & 14 \\
\hline 할 & 4 & \\
\hline
\end{tabular}

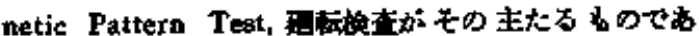
3 .

\section{6. その他の検在}

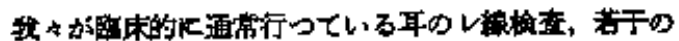

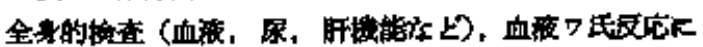

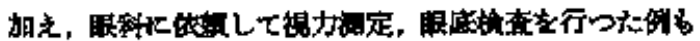

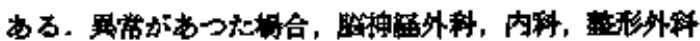

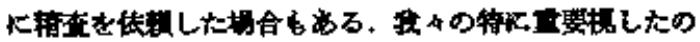

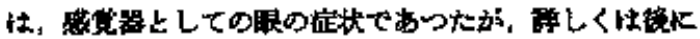
のベることとする。

\section{III. 粗田名}

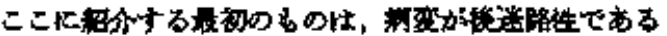

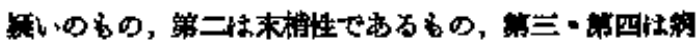

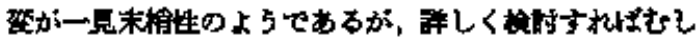

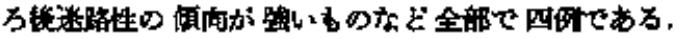

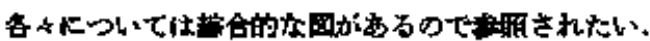

空国 I. 㕲元 16才 男 (因1)

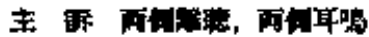

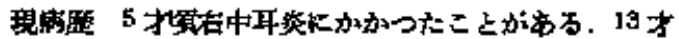

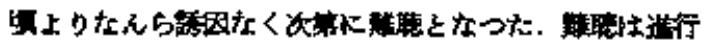

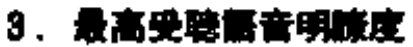

\begin{tabular}{|c|c|c|}
\hline & 右 (\%) & $t(\%)$ \\
\hline All Pass & 40 & $\$ 2$ \\
\hline Whocp: & 24 & \\
\hline Roncges & 80 & \\
\hline
\end{tabular}

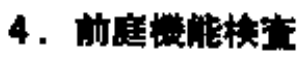

カロリー谈查 两CP

正策

ゴーシメトリー 正常

5. 两耳方向留

不阷 


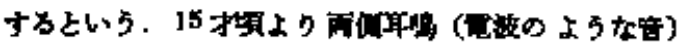

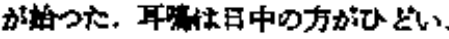

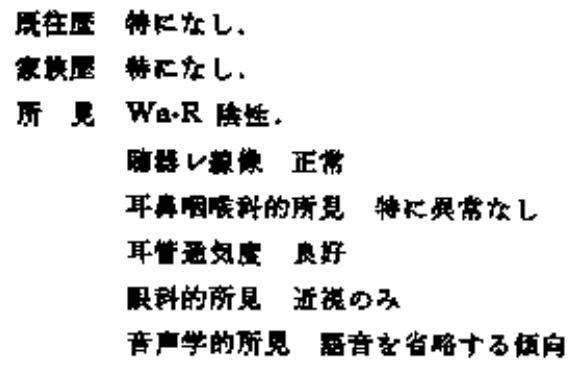

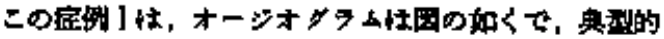

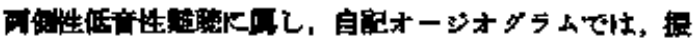

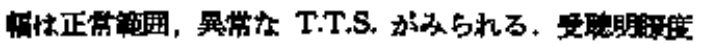

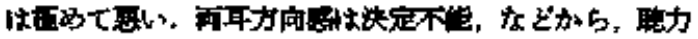

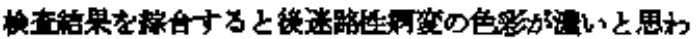
れる。

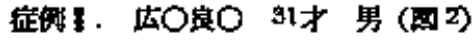

主 野
}

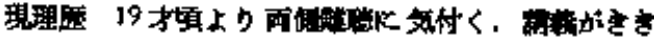

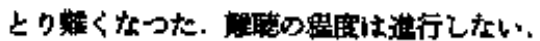

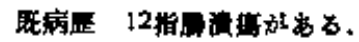

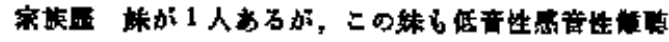
娄方。

房 見 Wa-R 陆性

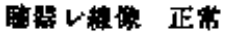

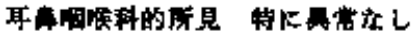

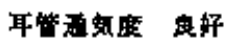
圆科的原見 沂视のみ. 底正常。

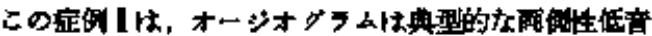

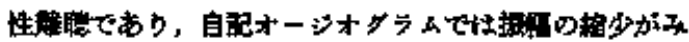
Bth, Tone decay Haw.

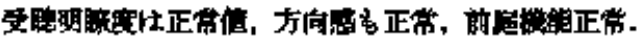

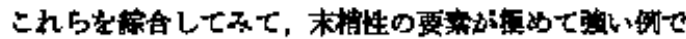

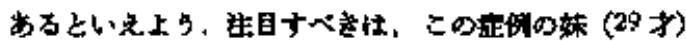

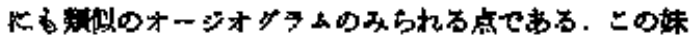

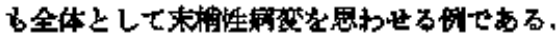

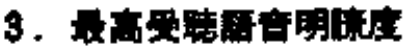

\begin{tabular}{|l|c|c|}
\hline & 右 (\%) & 真(\%) \\
\hline Al1 Pass & 78 & 4 \\
\hline $\begin{array}{l}1700 \text { ops } \\
\text { Hign Pass }\end{array}$ & 34 & \\
\hline 1200 coss & 48 & \\
\hline Low Pass & 48 & \\
\hline
\end{tabular}

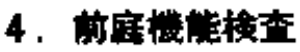

力口リー缺怘 正常

促提 正常

アニオメトリー 正異

5. 藏年方向虔

正労

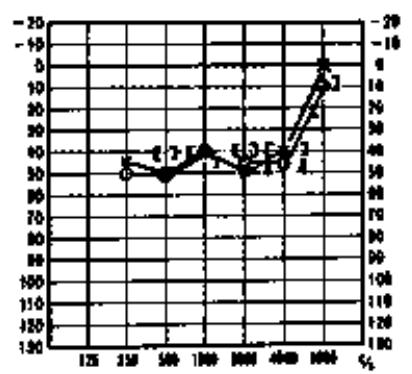

\begin{tabular}{|c|c|c|}
\hline & 需 & T. T. $\mathbf{s}$. \\
\hline a k t t & 2 & - \\
\hline $4 k c t$ & 2 & $=$ \\
\hline 保右 & 2 & $=$ \\
\hline $106 \frac{1}{t}$ & 3 & - \\
\hline t & $\$$ & $=$ \\
\hline $2 \sin \frac{\mathrm{z}}{2}$ & J & = \\
\hline
\end{tabular}

\section{広○部 31才合}

\section{1.おージグム}

\section{2. 固定周洨数自比才ージダラム}




\section{㐫○登○21才우}

\section{1.オージオのム}

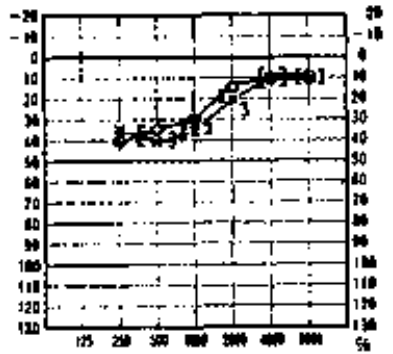

\section{2. 周定周流数自目オージオダラム}

\begin{tabular}{|c|c|c|}
\hline & - & T. T. 5. \\
\hline t & 10 & 14 \\
\hline AKC & & \\
\hline$\pi$ & 3 & $\overline{8}$ \\
\hline $1 \mathrm{kC} \cdot \frac{\mathrm{t}}{\mathrm{t}}$ & $\overline{2}$ & $I$ \\
\hline t & $\sqrt{2}$ & \\
\hline $0.5 \mathrm{kc}$ & $\overline{2}$ & 100 \\
\hline
\end{tabular}

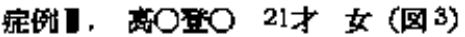

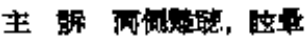

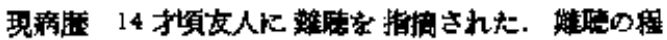

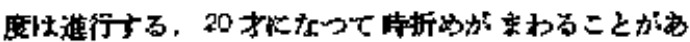

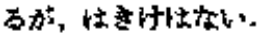

\section{厓往是 特下なし

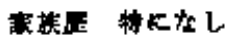

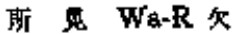

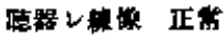

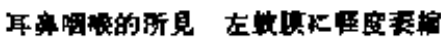

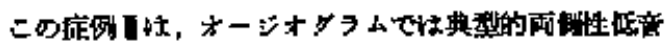

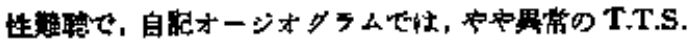

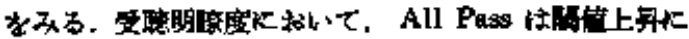

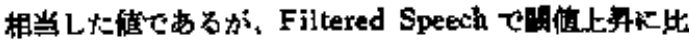

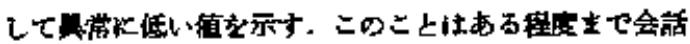

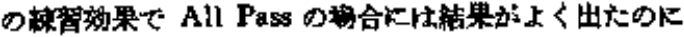

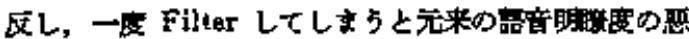

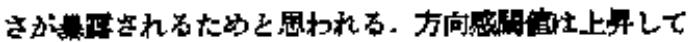

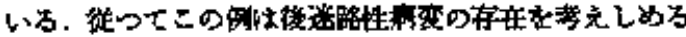
むのであら5.

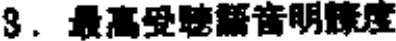

\begin{tabular}{|c|c|c|}
\hline & 右 $(\%)$ & t $(\%)$ \\
\hline All Pass & $M$ & 52 \\
\hline 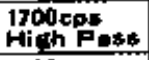 & 88 & \\
\hline $\begin{array}{l}1200 \operatorname{cps}^{\circ} \\
\text { Lowst }\end{array}$ & 8 & \\
\hline
\end{tabular}

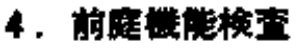

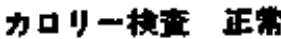

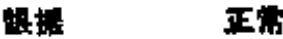

$$
\begin{aligned}
& \text { コニオメトリー 柔い }
\end{aligned}
$$

5，闻耳方向电

不增

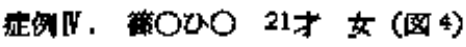

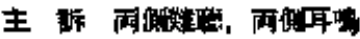

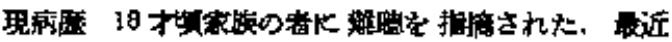

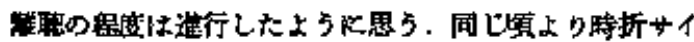

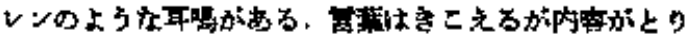
比くい,

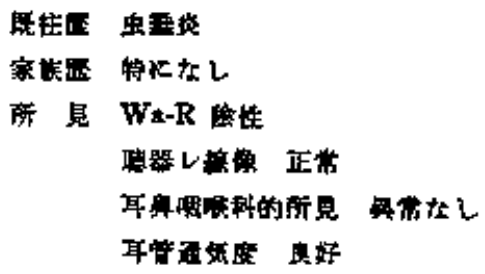

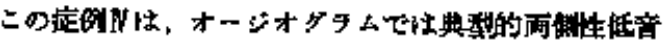

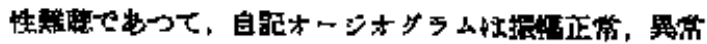

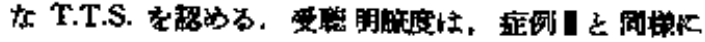

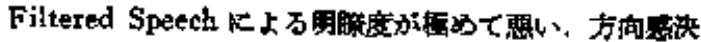
定不境.

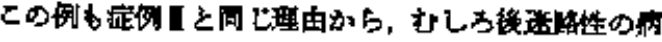

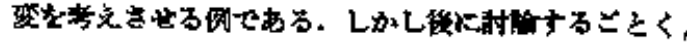

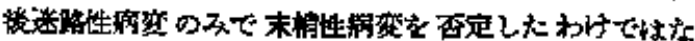




\section{落OU一 214우}

\section{1. オージオグラム}

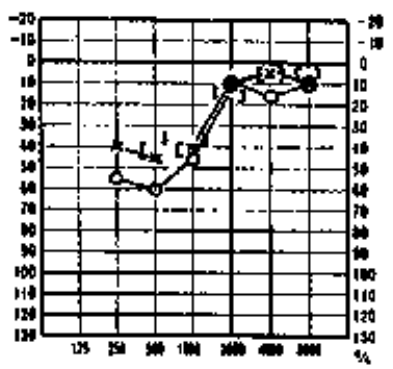

2、固定周法数自杞オージオグラム

\begin{tabular}{|c|c|c|}
\hline & - & T. T. $\mathbf{S}$. \\
\hline 淿古 & 2 & 20 \\
\hline 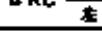 & 4 & 14 \\
\hline E & 4 & 10 \\
\hline KL & 3 & \\
\hline a AKc 䌸 & & \\
\hline E & 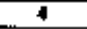 & \\
\hline
\end{tabular}

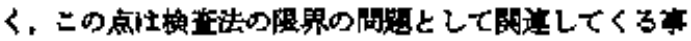
桐でる。

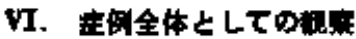

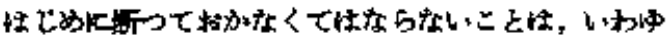

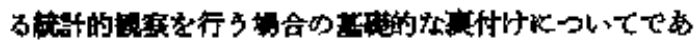

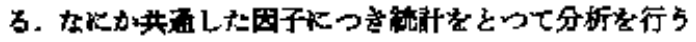

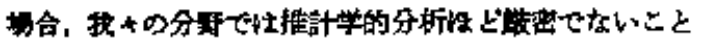

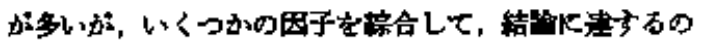

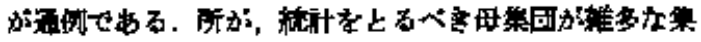

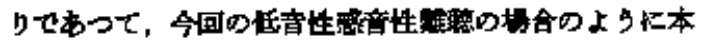

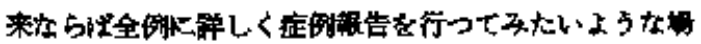

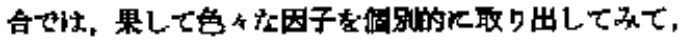

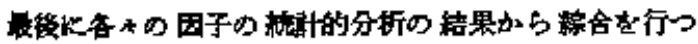

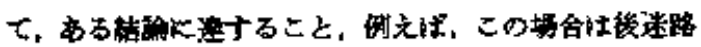
性であるとか，宋㧹性であるとかか，正いいかというこ

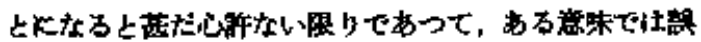

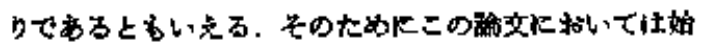

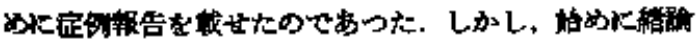

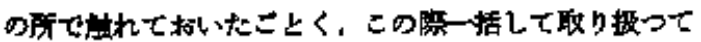

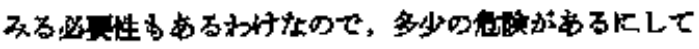

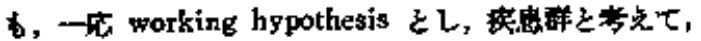

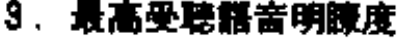

\begin{tabular}{|c|c|c|}
\hline & 古(\%) & 左 (\%) \\
\hline All Pass & 25 & 96 \\
\hline $\begin{array}{l}1700 \mathrm{pos} \\
\text { Hiph Pose }\end{array}$ & 20 & 48 \\
\hline $\begin{array}{l}\text { l200eps } \\
\text { Low Pses }\end{array}$ & 6 & 24 \\
\hline
\end{tabular}

4. 前庭䍒能湌查 カロリー慗左DP 背振 正常 コニオメトリー 正常

5. 雨耳方向在

不制

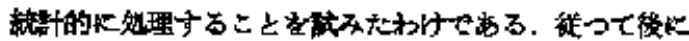

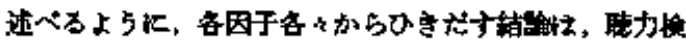

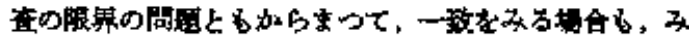

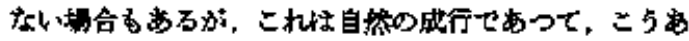
つてしかるべすのと我々情えている。

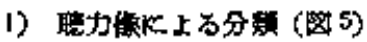

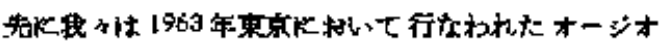

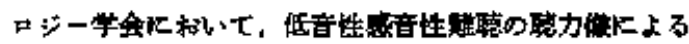

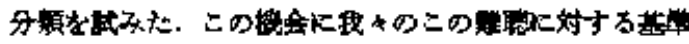

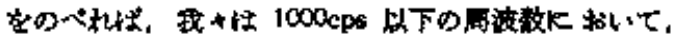

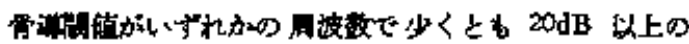

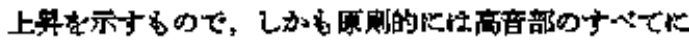

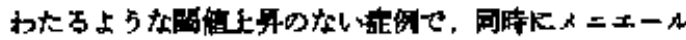

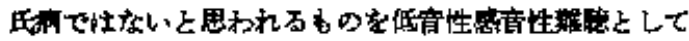
取り报つている。

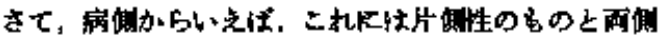

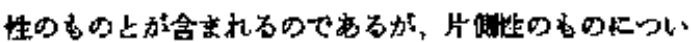

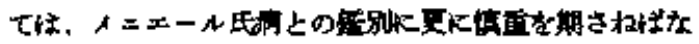

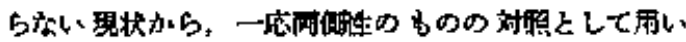

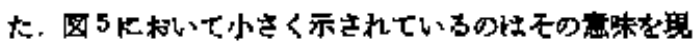

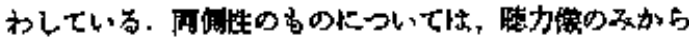




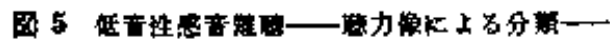

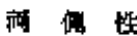

\section{A. 琶的}

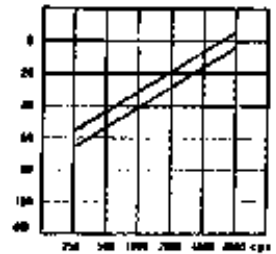

B. 非梨的

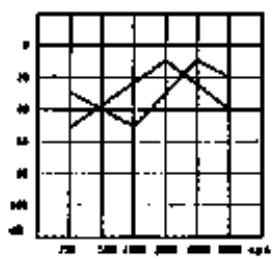

占证住

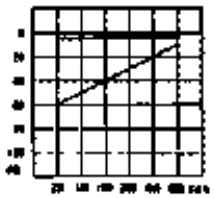

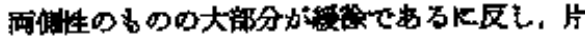

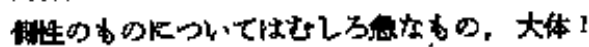

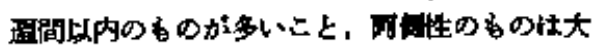

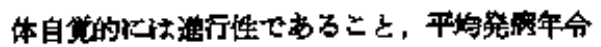

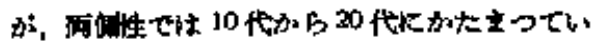

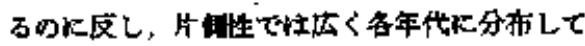

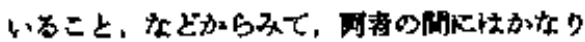

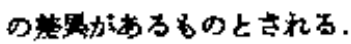

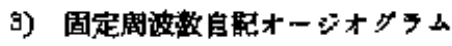
(图 7, a, 9)

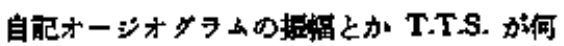

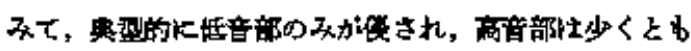

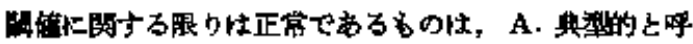

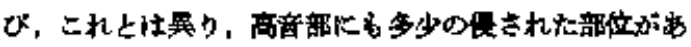

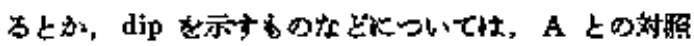

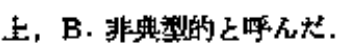

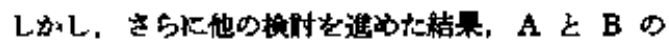

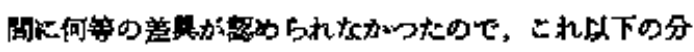

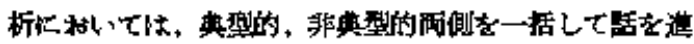

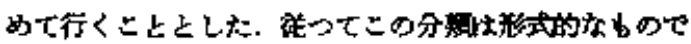

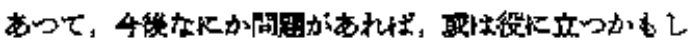

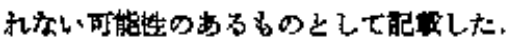

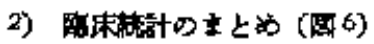

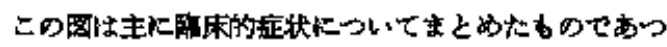

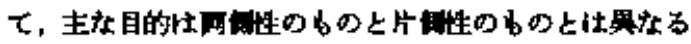

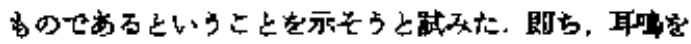

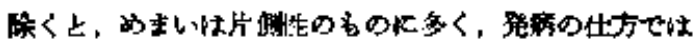

图 6

的床統俨まとめ

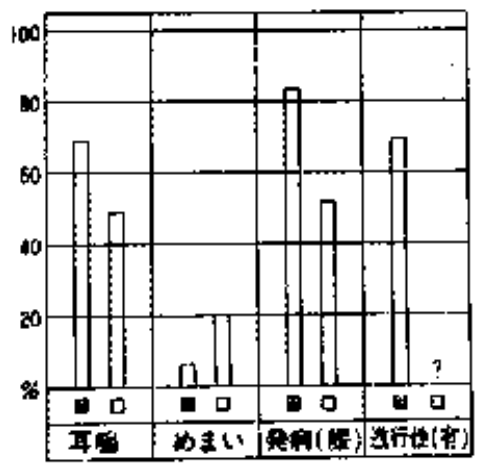

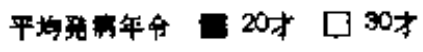

a mantis

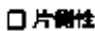

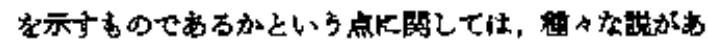

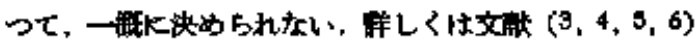

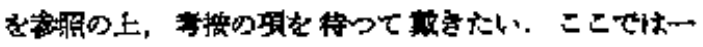

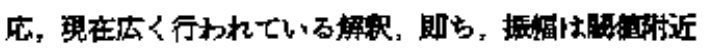

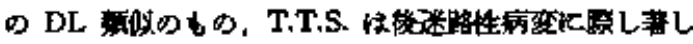

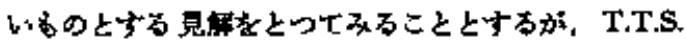

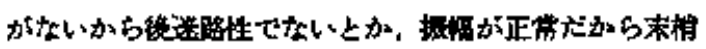

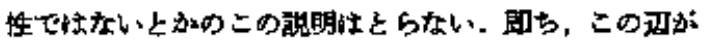

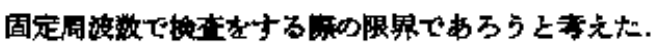

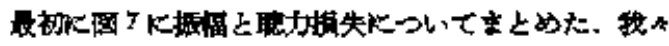

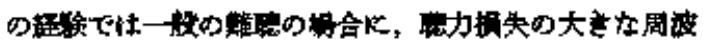

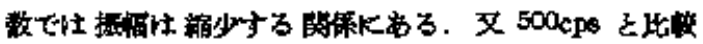

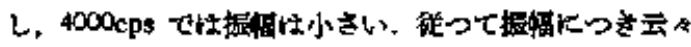

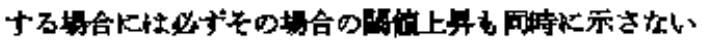

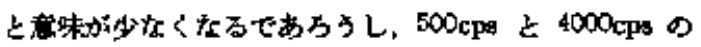

27

国宝周波数日周オージオクラム

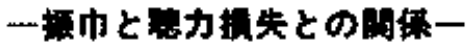
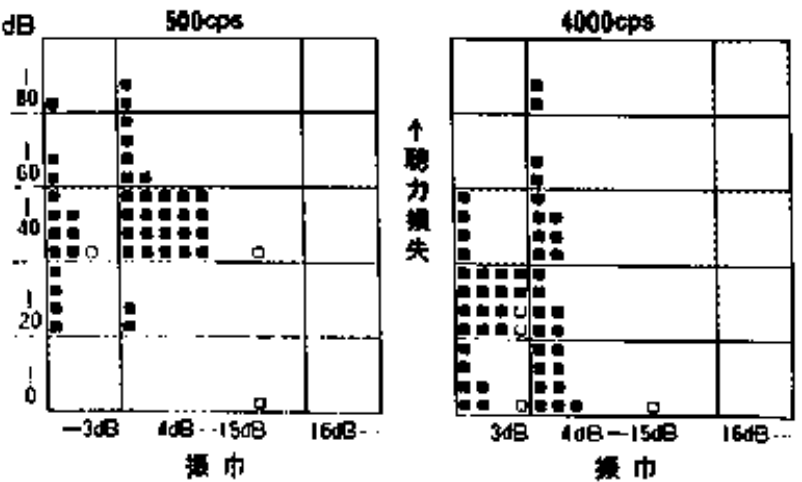


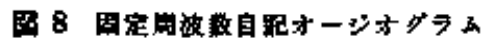
-T.T.S.-

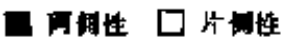

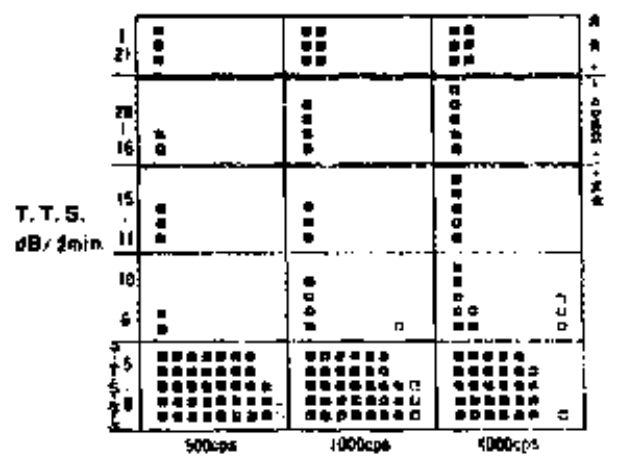

10 T.TS. (500 cps \& $4000 \mathrm{cps})$ 分布此韧

口两国姓 口片的性

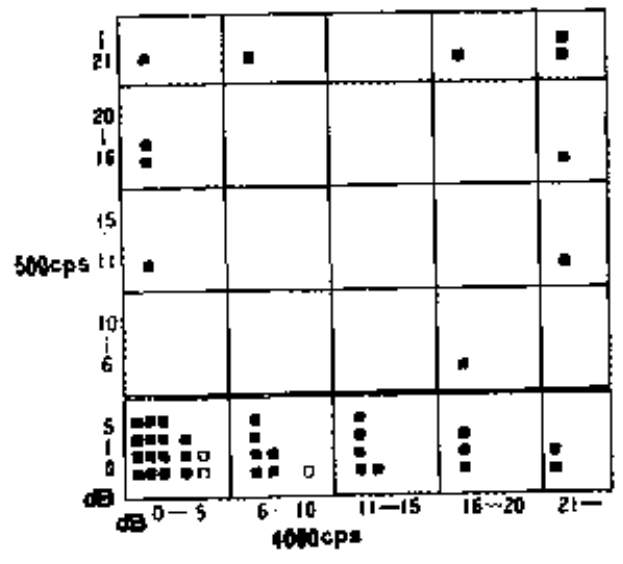

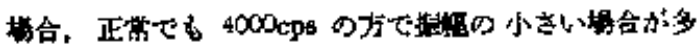

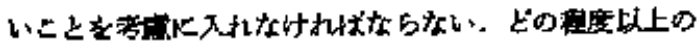

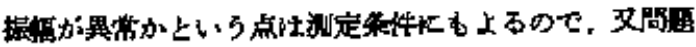

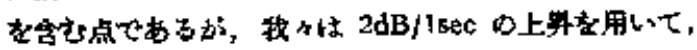

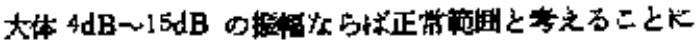

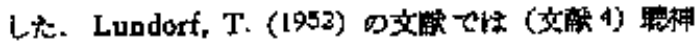

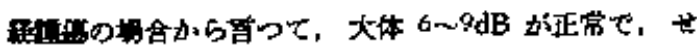
いせい広く見弱つてる 5〜20dBであろうとしている。

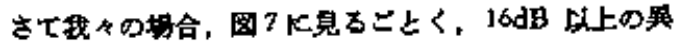

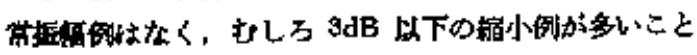

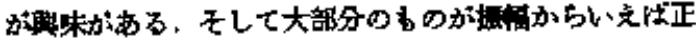

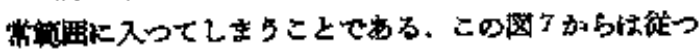

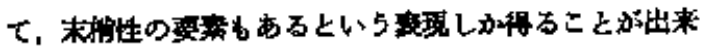

Fsb.

次の图日大我性 $500 \mathrm{cps}, 1000 \mathrm{cps}, 4000 \mathrm{cps} k$ 始け

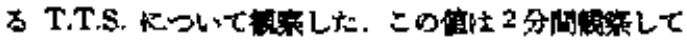

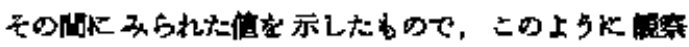

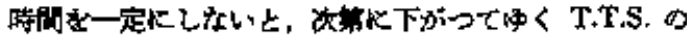

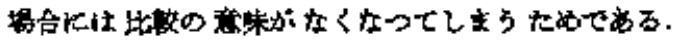

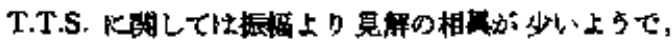

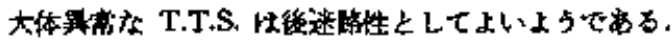
ただし，この逆忙正しく机，現在 T.T.S. 忙 T.D.T.

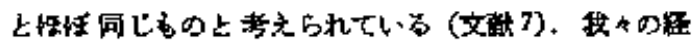

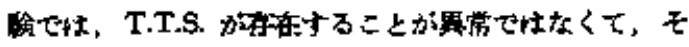

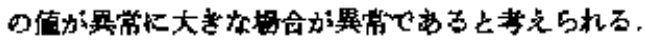

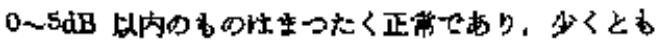

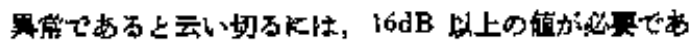

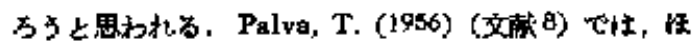

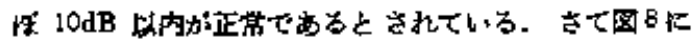

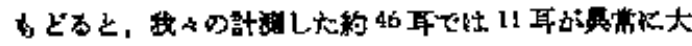

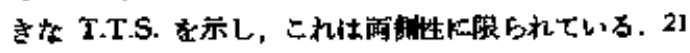

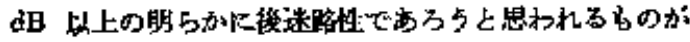

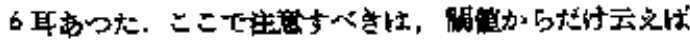

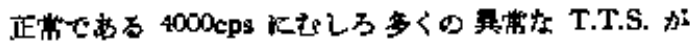

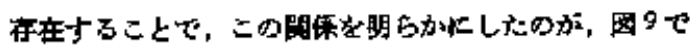

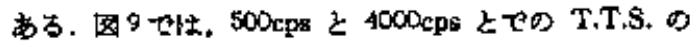
乐在の此落汀つているが，この禹者の T.T.S. の间に

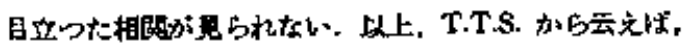

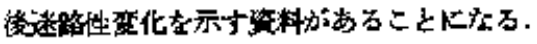

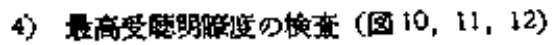

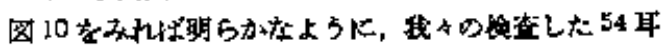

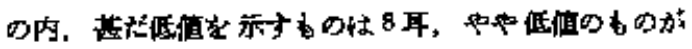

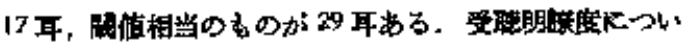

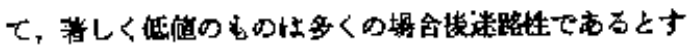

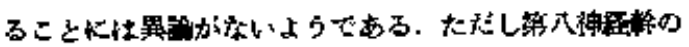

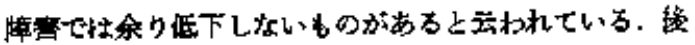

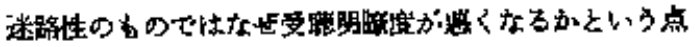

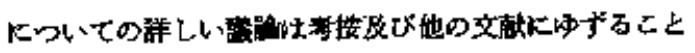

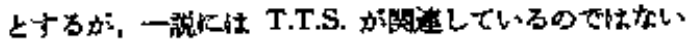

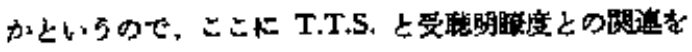

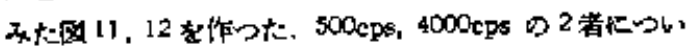
て行つてある。

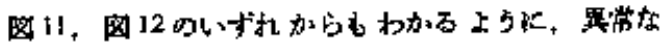

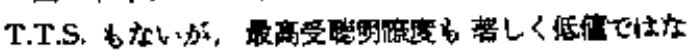

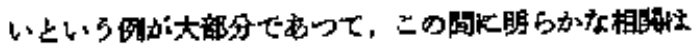

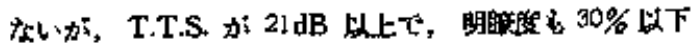




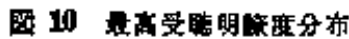

口时制生 $\square$ 片僛

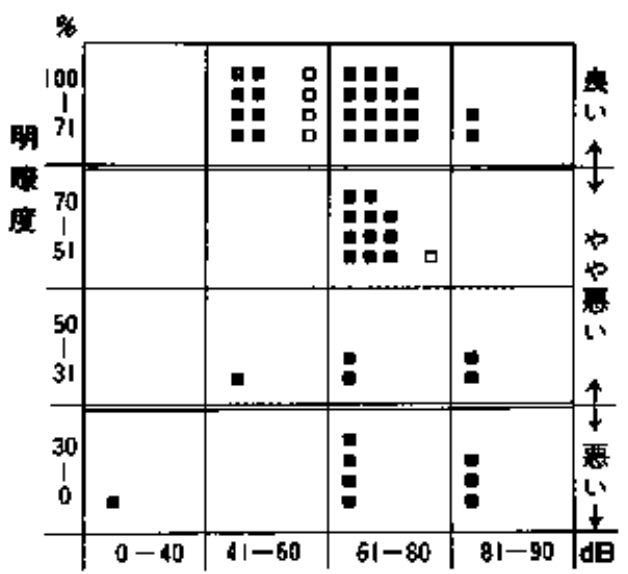

圈 11 T.T.S. $(500 \mathrm{cps})$ と斯

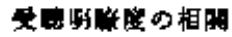

两两绯 口片划性

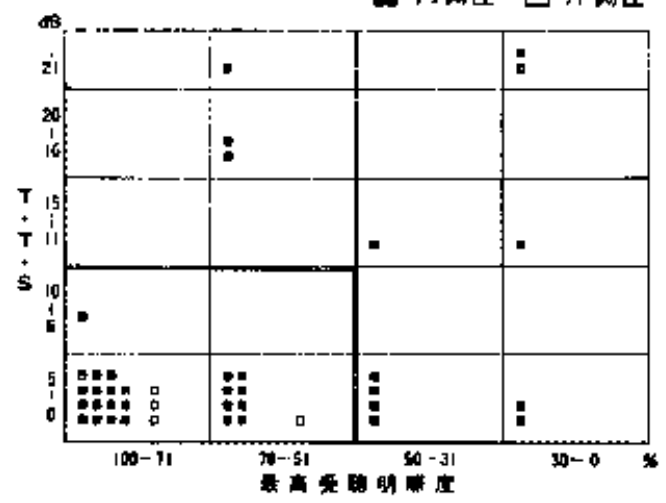

图 32 T.T.S. $(4000 \mathrm{cps})$ 上期花

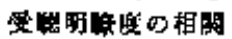

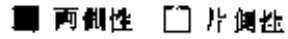

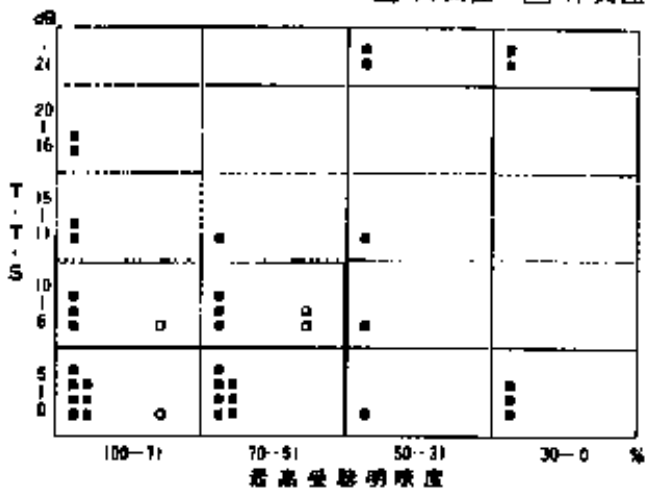

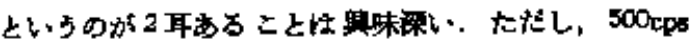

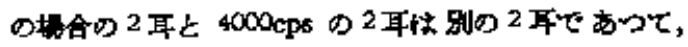
500eps D坦合仕2人の患英 01 耳

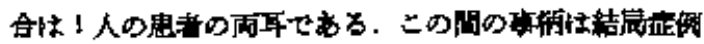

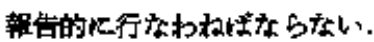

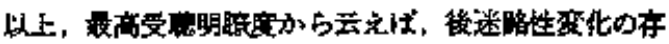

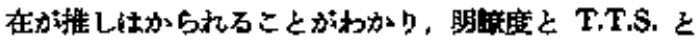

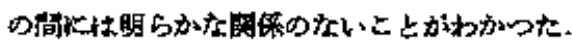

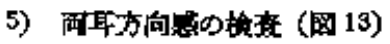

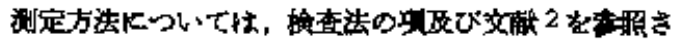

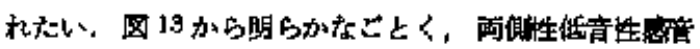

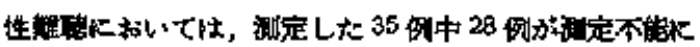

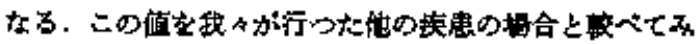

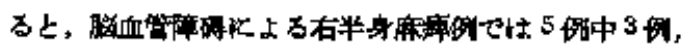

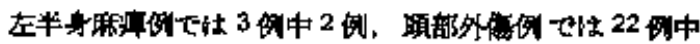

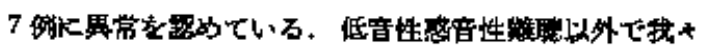

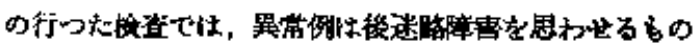

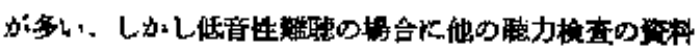

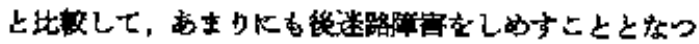

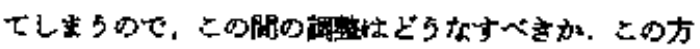

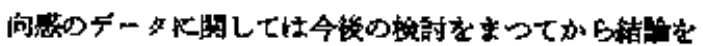
下レたい.

图 13 両耳方向感

\begin{tabular}{|c|c|c|c|}
\hline & 正 学 & 获大型 & 不 能 \\
\hline 两 珄 & 6 & 1 & 28 \\
\hline 片培 & 2 & 0 & 1 \\
\hline
\end{tabular}

正营 $2 \mathrm{~cm}$ 以内

地大昰 $2 \mathrm{~cm}$ 以上

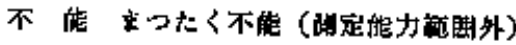

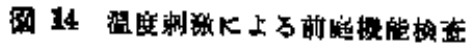

\begin{tabular}{|c|c|c|c|c|}
\hline & 正常皮恒 & 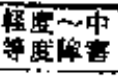 & 采 区 店 & 台 \\
\hline 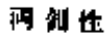 & 14 例 & 7湖 & 3 体 & 24 例 \\
\hline 战蛙 & 3任 & 0 & 0 & 9销 \\
\hline
\end{tabular}

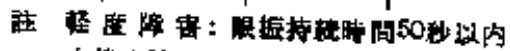

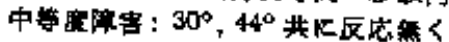

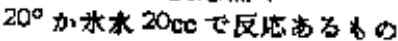

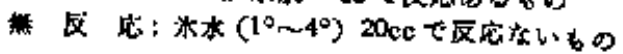




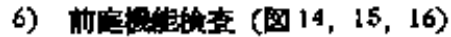

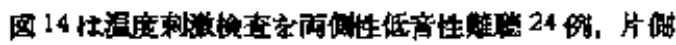

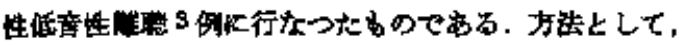

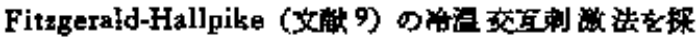

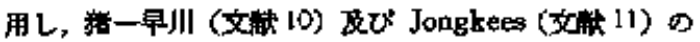

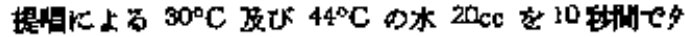

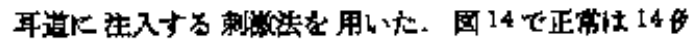
$58 \%$ を占め，眼振力向位位性 (Directional Prepon

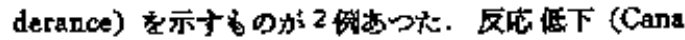

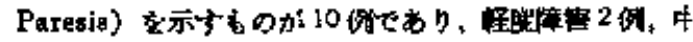

\section{四 Is \\ 広竞の自発眼振泟例}

\begin{tabular}{|c|c|c|c|}
\hline 眼 & & 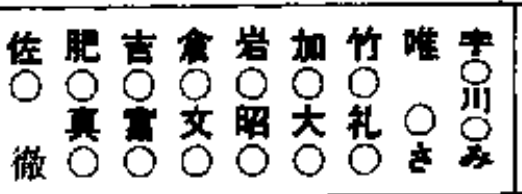 & in \\
\hline 白 単 性 & $\left\langle\begin{array}{c|c|c|c|} & 0 \\
0 & 0\end{array}\right\rangle$ & 00 & 2 \\
\hline 注措及び柆位性 & 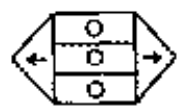 & 0000000 & 7 \\
\hline 丽位 & $\rightarrow$ & $0 \quad 0$ & 2 \\
\hline 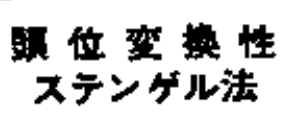 & $\downarrow$ & 0000 & 4 \\
\hline
\end{tabular}

图 16

注梘及び梅位性眼振

\begin{tabular}{|c|c|c|c|c|c|c|c|}
\hline & 侤O 桄 & GOCO & 吉Otol & 10女o & 岩OBO & moto & $40110 *$ \\
\hline 眼 & & $\frac{b}{0} \frac{1}{0} \Rightarrow$ & & & $\sqrt{0}$ & & 0 \\
\hline レンツェル & & & $\left\langle\sqrt[4]{\frac{1}{a}} \Rightarrow\right.$ & $\Leftrightarrow$ & 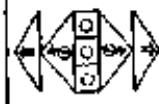 & 50 & 4 \\
\hline
\end{tabular}

$\rightarrow$ 小打性

$\Rightarrow$ 中打性济打性

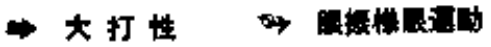




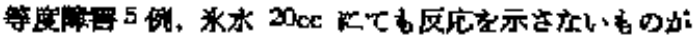

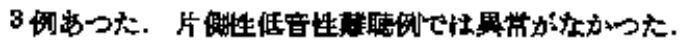

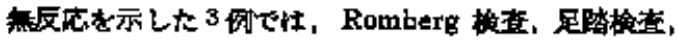

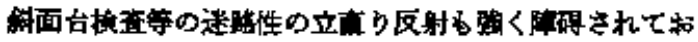

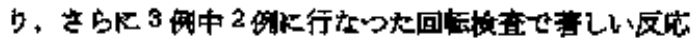

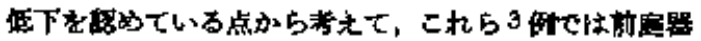

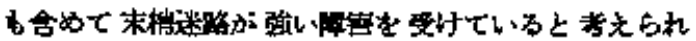
万.

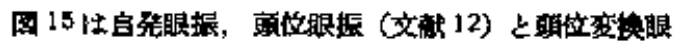

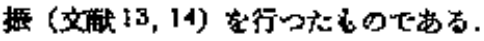

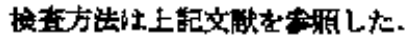

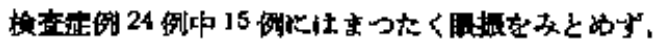

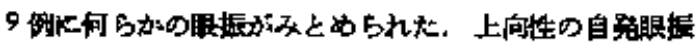

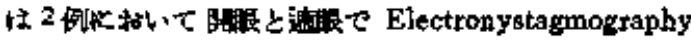

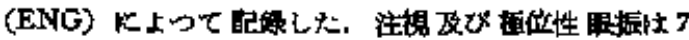

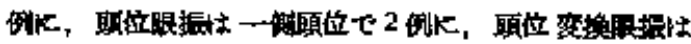

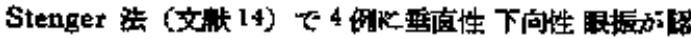
やられた.

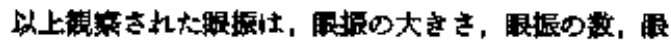

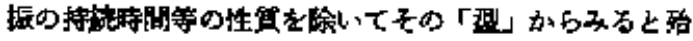

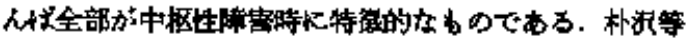

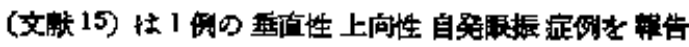

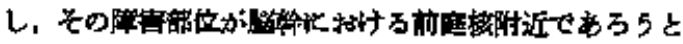

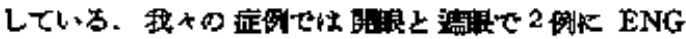

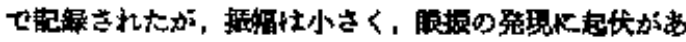

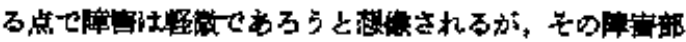

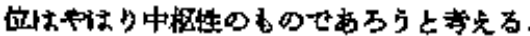

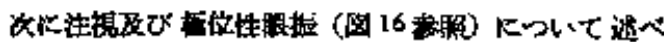

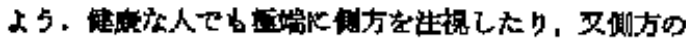

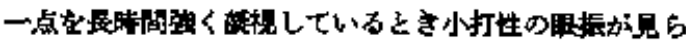

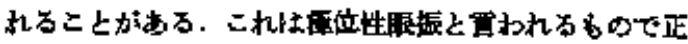

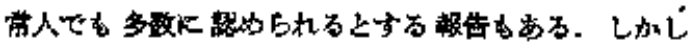

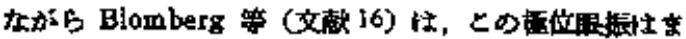

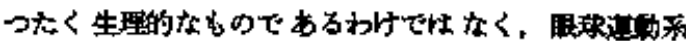

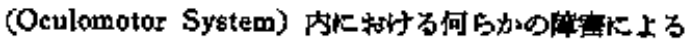
ののてるると速べている.

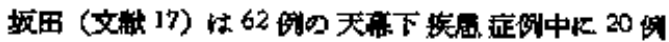

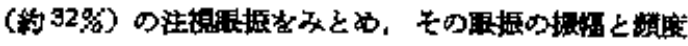

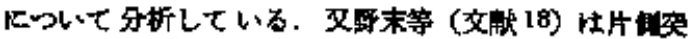

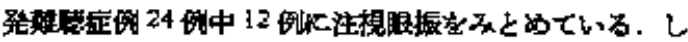

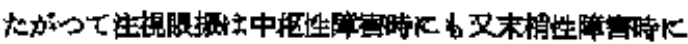

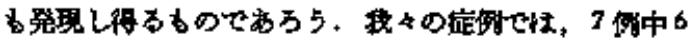

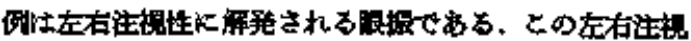

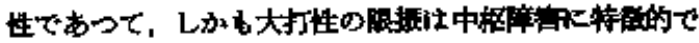

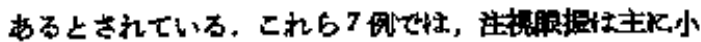

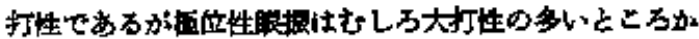
ら，何らかの中相部の在を考光た。

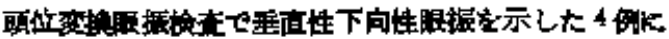
ついで考莱してみ上る。

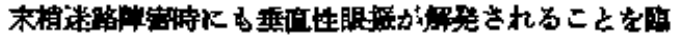

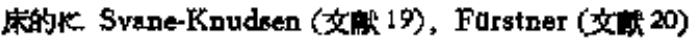

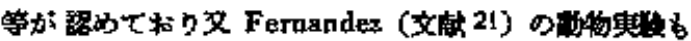

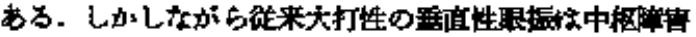

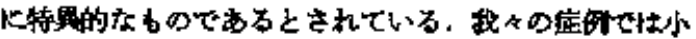

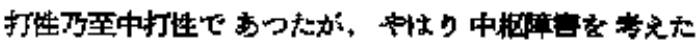
W.

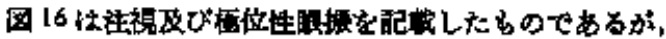

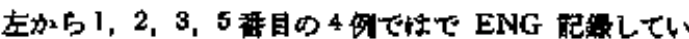
๖.

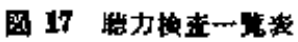

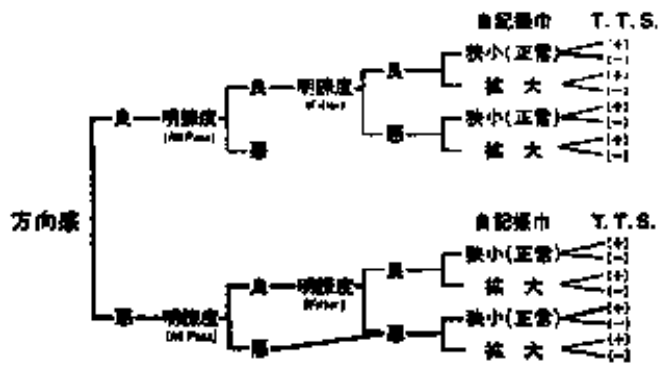

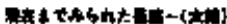

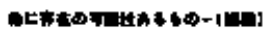

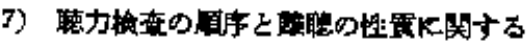

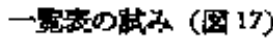

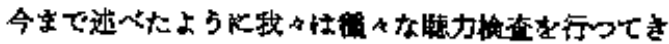

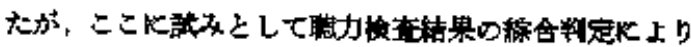

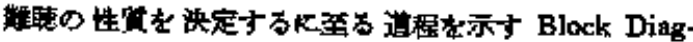

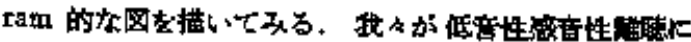

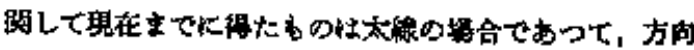

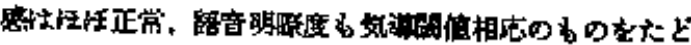

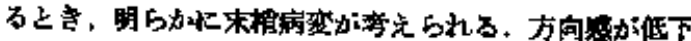

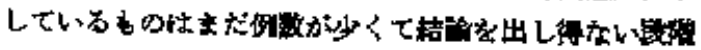

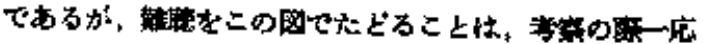
整理の目安比标ると考充られる。

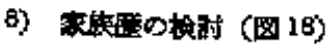

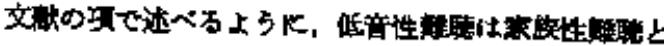


图 18

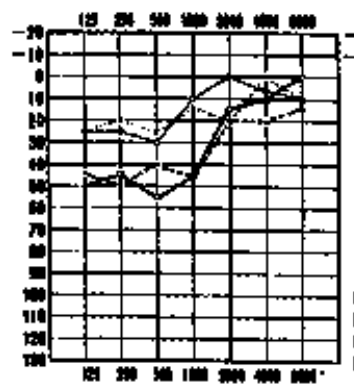

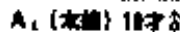

A, (int) $26=$ \&

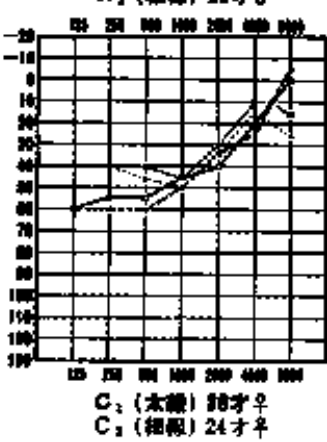

C, (繶) 24 才辛

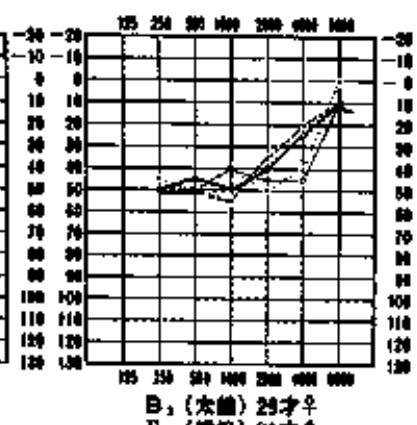

$B,($ in $31 \neq+$

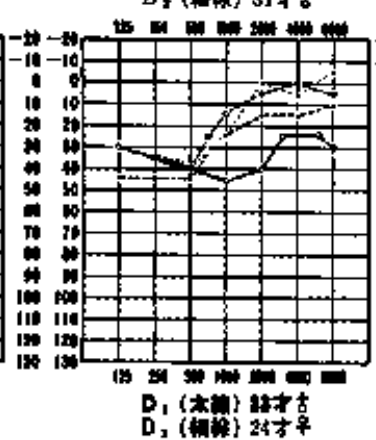

D, (蛙) 24 落
实族性に現われ

た低者性难艘

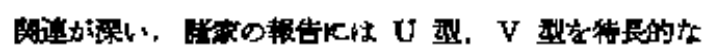

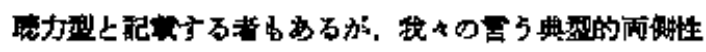

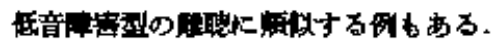

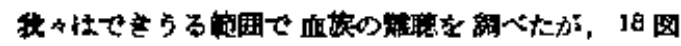

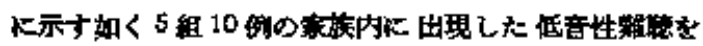

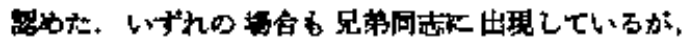

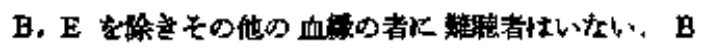

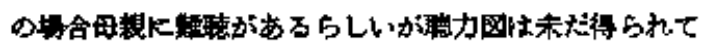

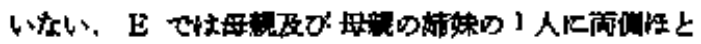

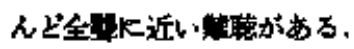

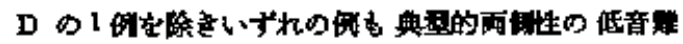

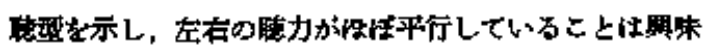
潄、

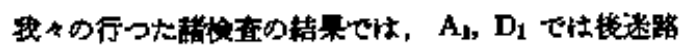

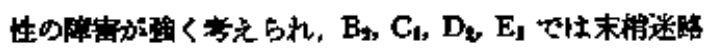

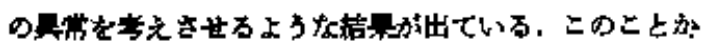

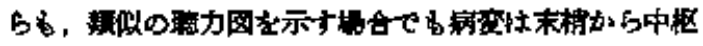

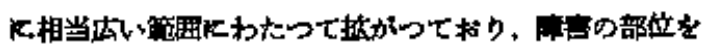

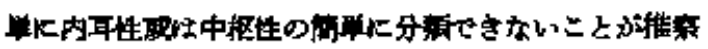
される。

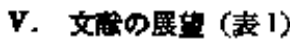

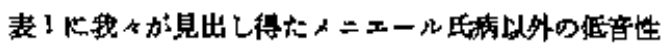

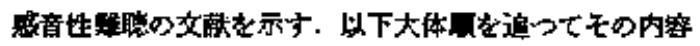

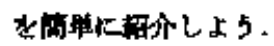

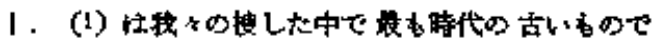

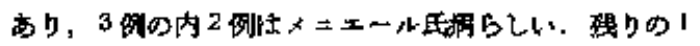

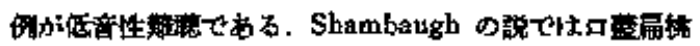

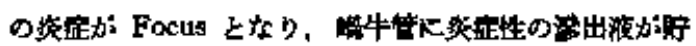

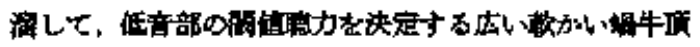

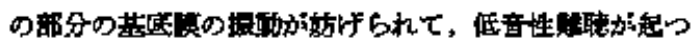

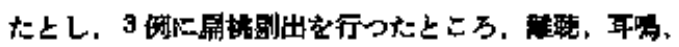

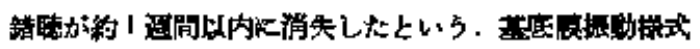

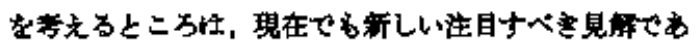

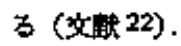

(2) 世 Willians のい5めむいのない内リンパ水国

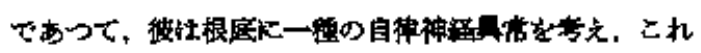

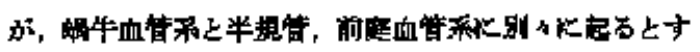

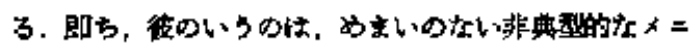

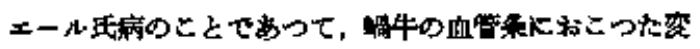

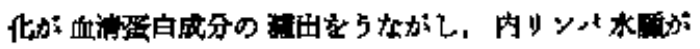




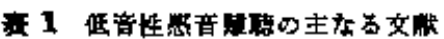

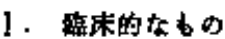

1) Shambaugh 1935 内耳出蒚努涚

2) Williams 1945 Endolymphatic Hydrops without Vertigo

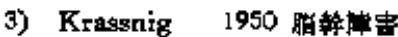

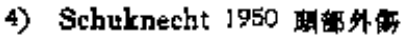

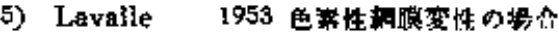

6) Lundborg 1955 痤儌告

7) Gravendeel 1960 学位到文

d) Carhart 1962 Labyrinthine Otosclerosis

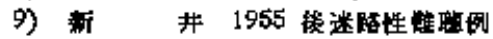

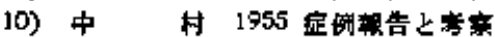

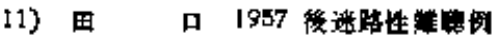

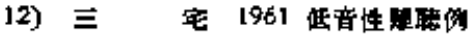

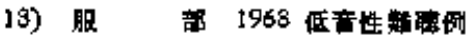

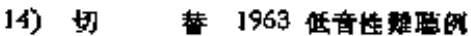

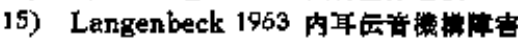

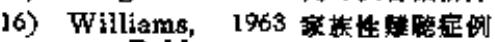
Rablee

1 - 实粭的在 b 0

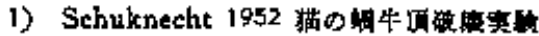

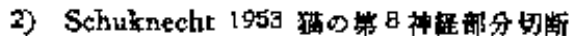

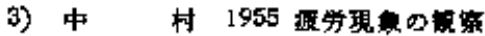

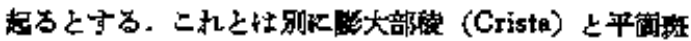

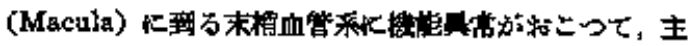

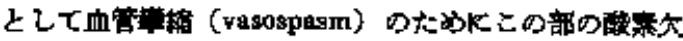

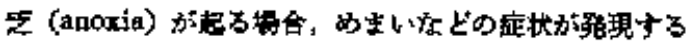

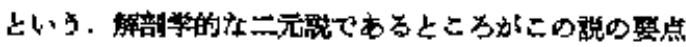

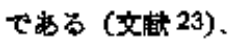

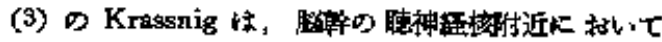

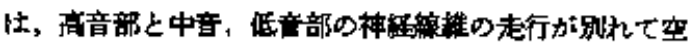

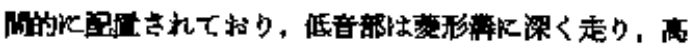

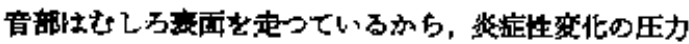

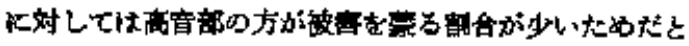
している. 彼の行つたのは 2 症例についての啹告て，

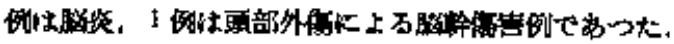

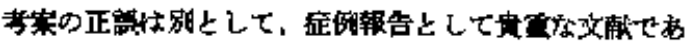
万(文触 24).

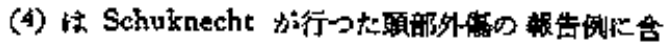

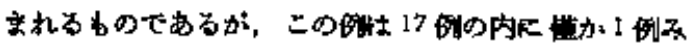

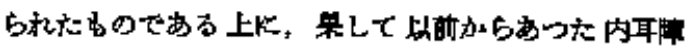

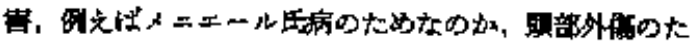

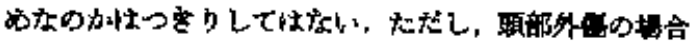

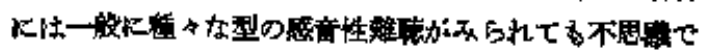

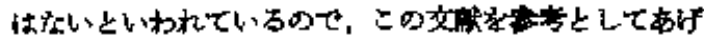

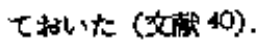

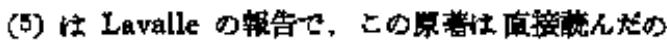
『外，1954年の A.M.A. Arch. Otolaryng. の拈

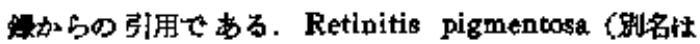

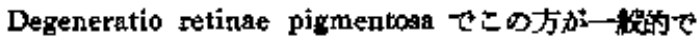

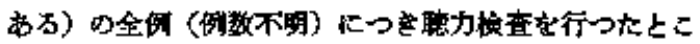

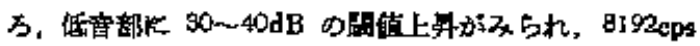

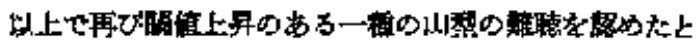

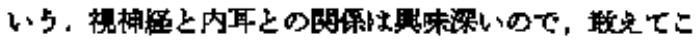

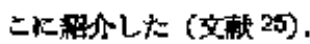

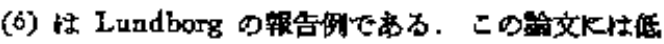

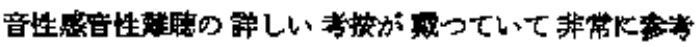

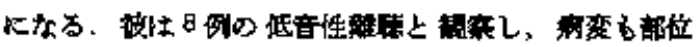

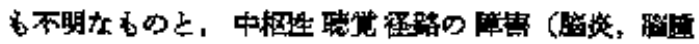

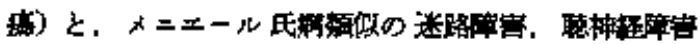
(acoustic neuritis) 生どをあけでいる，結成，彼の結

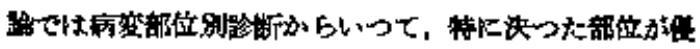

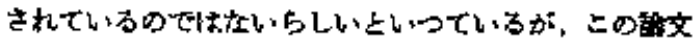

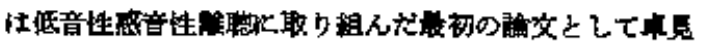
である(亩䔕 26)。

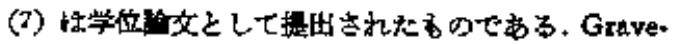

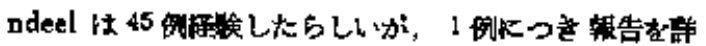

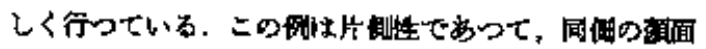

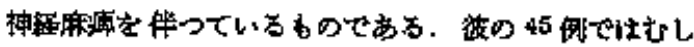

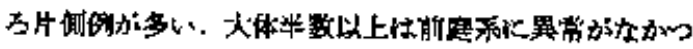
たといら、またリ/

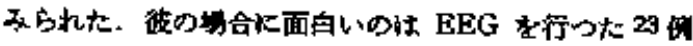

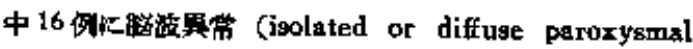

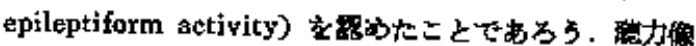

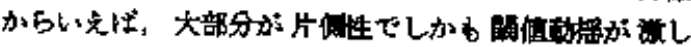

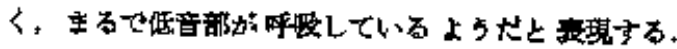

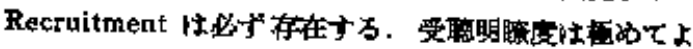
い. Langenbeck の noise audiometry はラヒン被霹

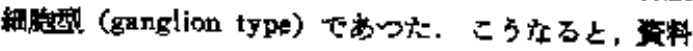

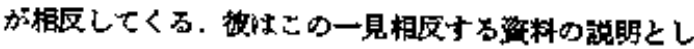

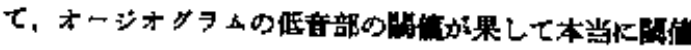

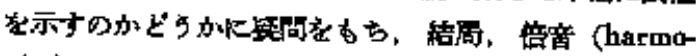

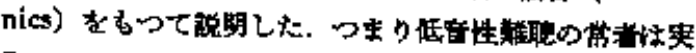

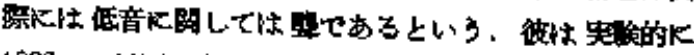

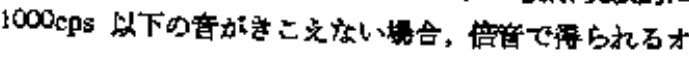

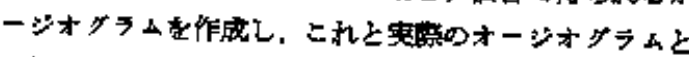

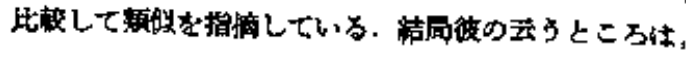




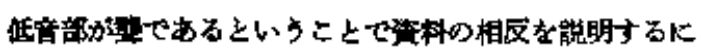

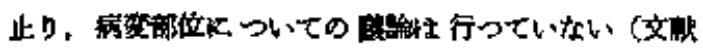
2).

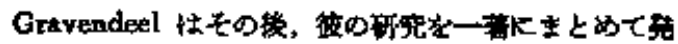

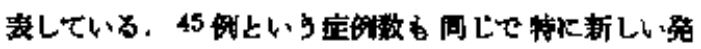

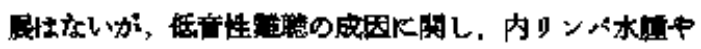

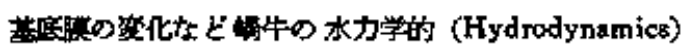

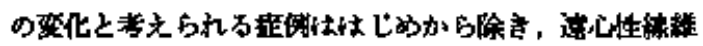

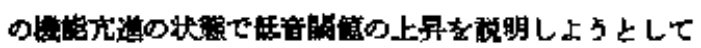

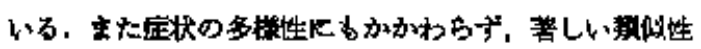

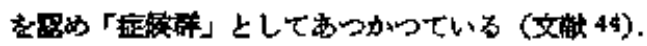

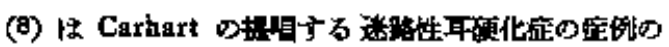

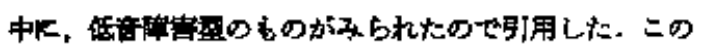

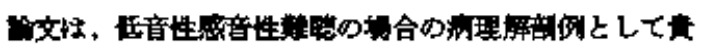

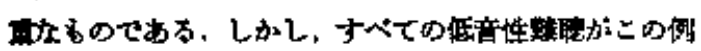

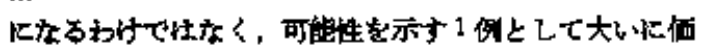

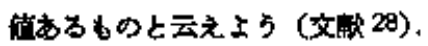

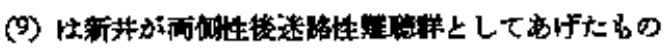

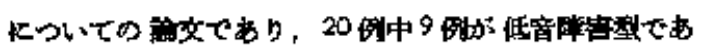

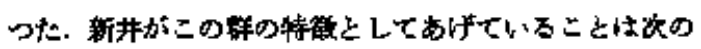
9コセb.

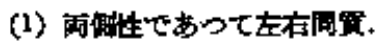

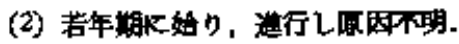

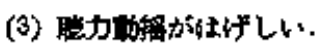

(4) 部音明因度が著しく低下している。

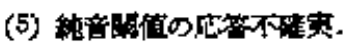

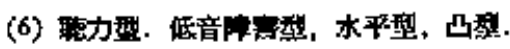

(?) $\mathrm{DL}$ 不息.

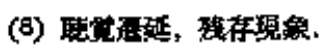

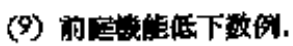

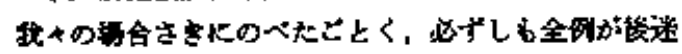

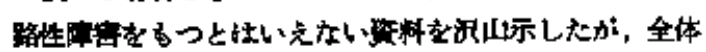

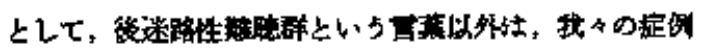

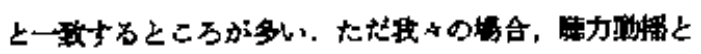

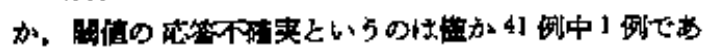

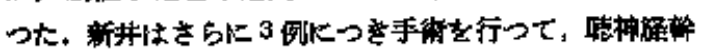

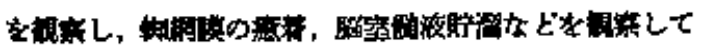

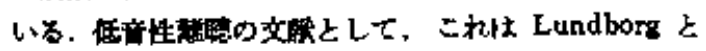

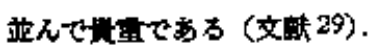

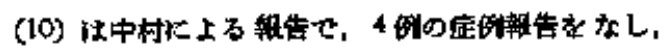

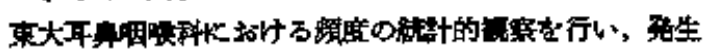

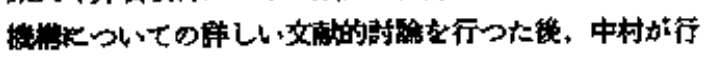
DK 200 400cps o Band Noise, 105 110 phon, 60

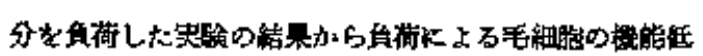

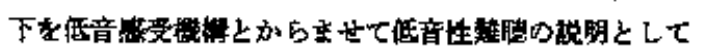

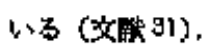

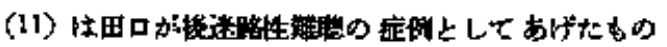

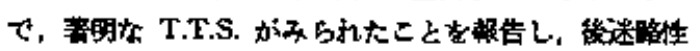

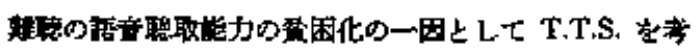

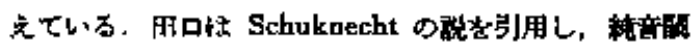

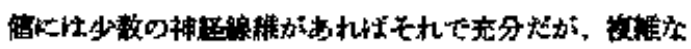

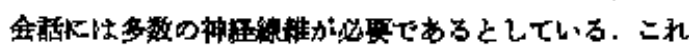

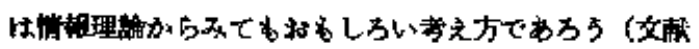
32).

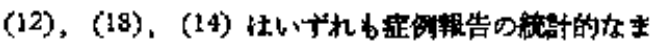

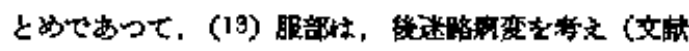

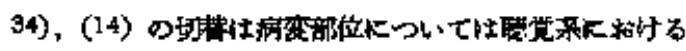
色んなとこが考えられるとしている(交觔35)。

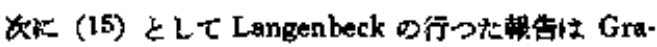

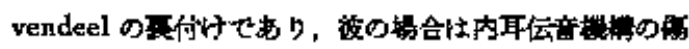

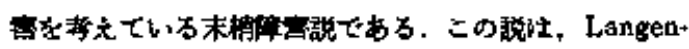

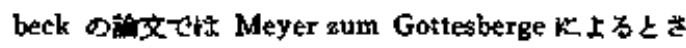

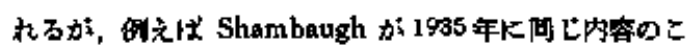

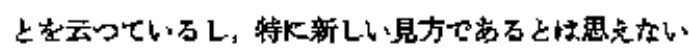
(文䉼 98 ).

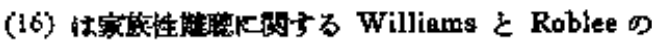

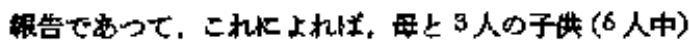

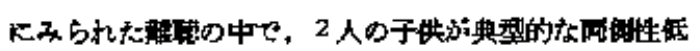

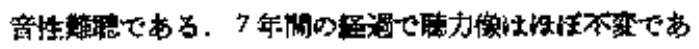

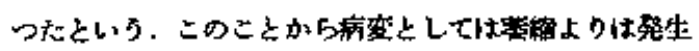

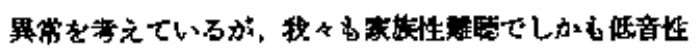

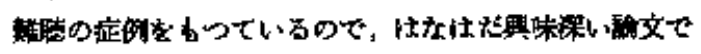
あ万(献 39 ).

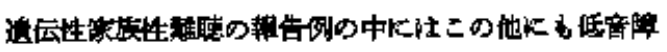

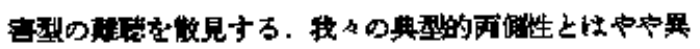

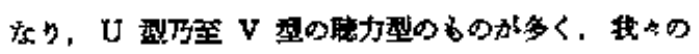

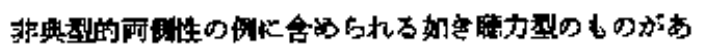

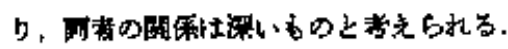

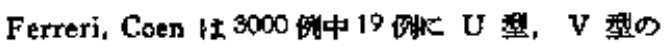

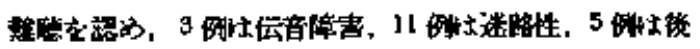

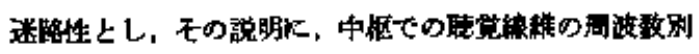

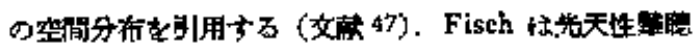

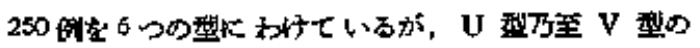

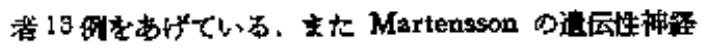

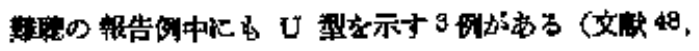

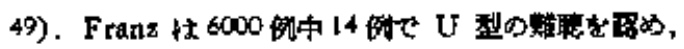




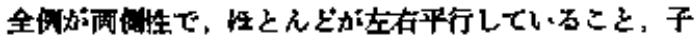

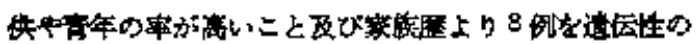

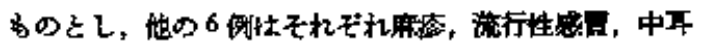

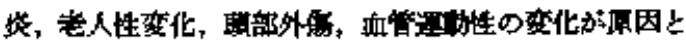

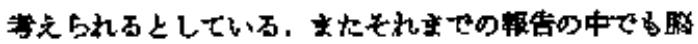

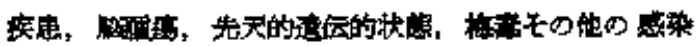

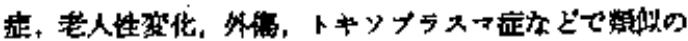

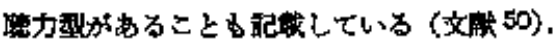

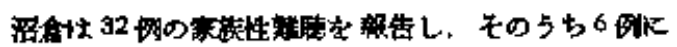

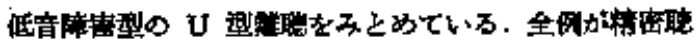

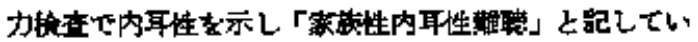

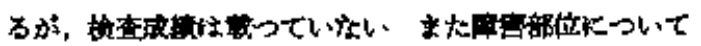

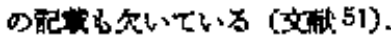

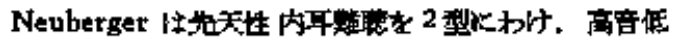

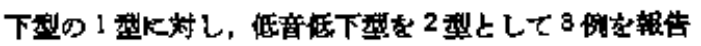

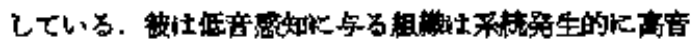

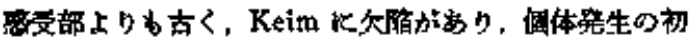

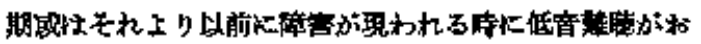

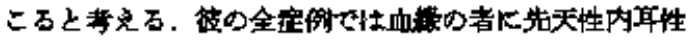

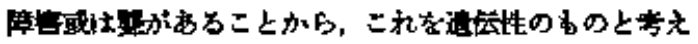

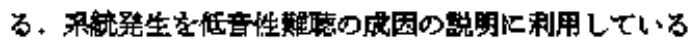

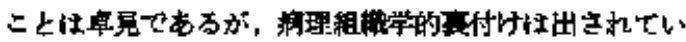

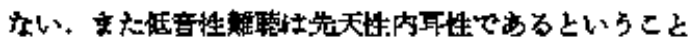

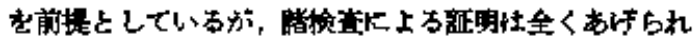

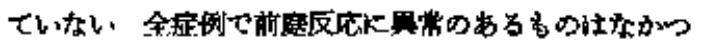

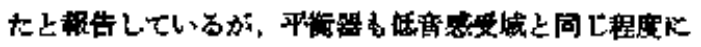

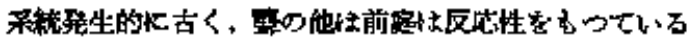

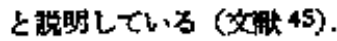

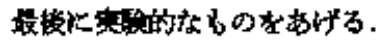

I. (1) (表1) \& Schuknecht \& Neff の行つt

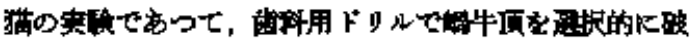

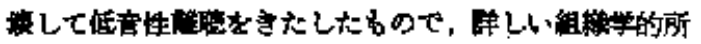

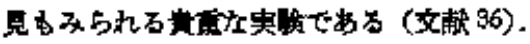

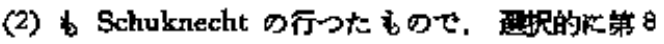

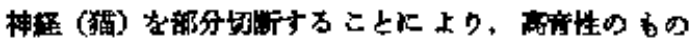

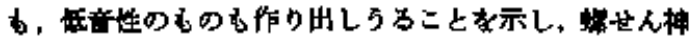

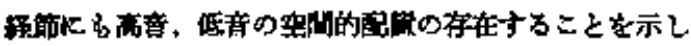
ている (就37)

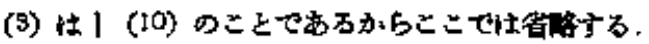

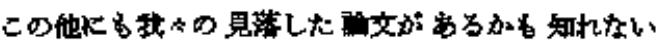

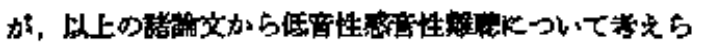

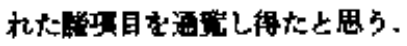

\section{VI. $*$ 措}

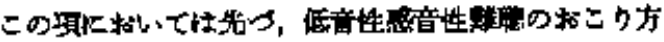

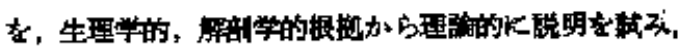

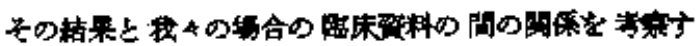

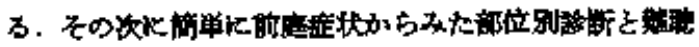

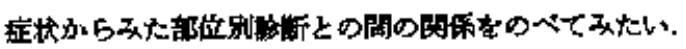

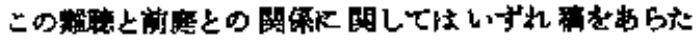

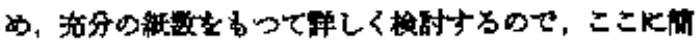

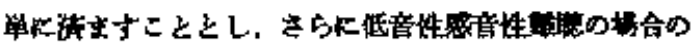

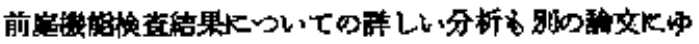
ぢこととする。

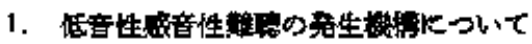

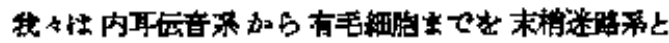

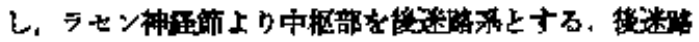

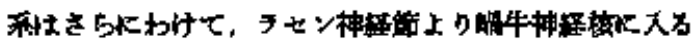

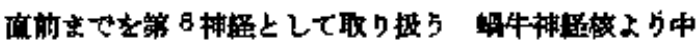

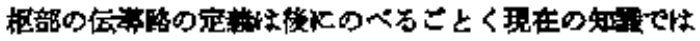

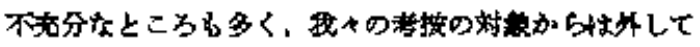
あるのでここではのべいらをにした。

\section{a 、 末梢道佲系}

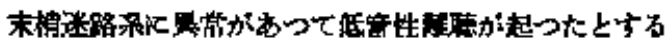

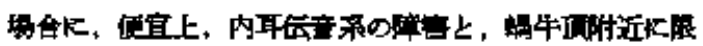

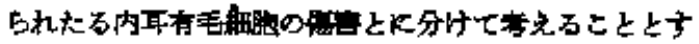

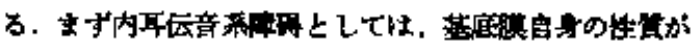

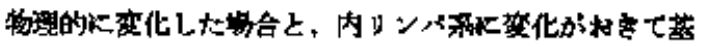

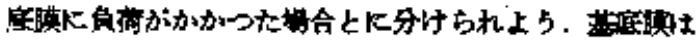

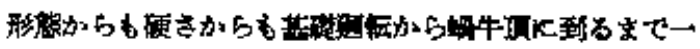

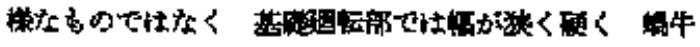

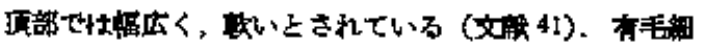

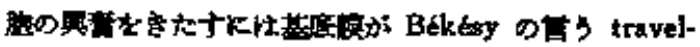

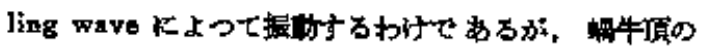

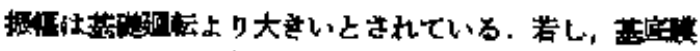

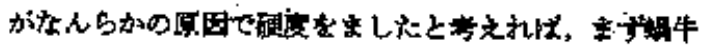

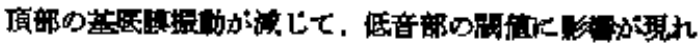

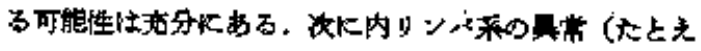

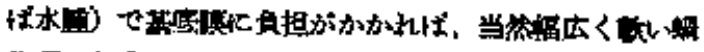

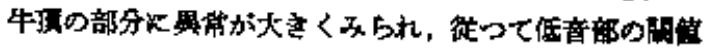

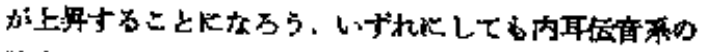

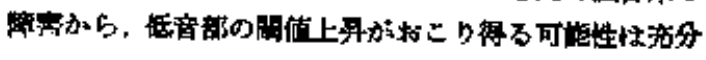

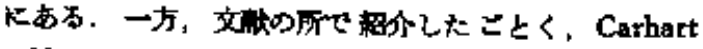

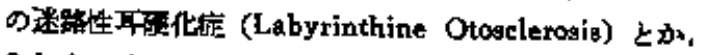

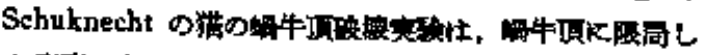

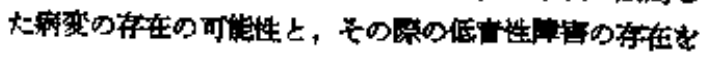




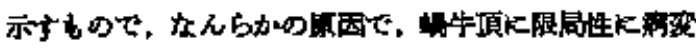

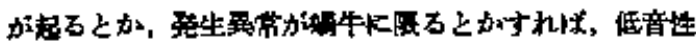

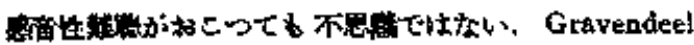

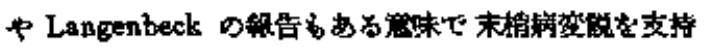

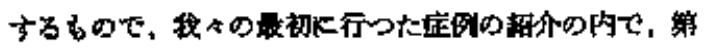

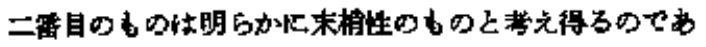

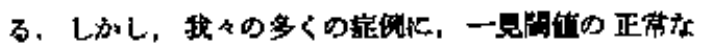

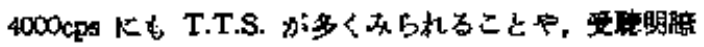

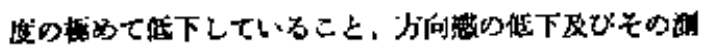

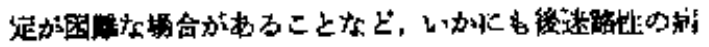

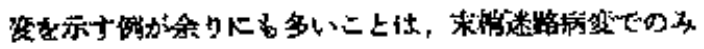

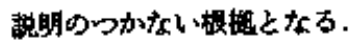

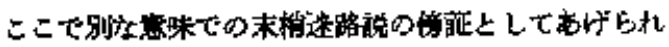

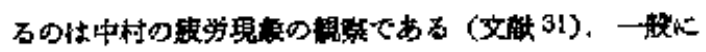

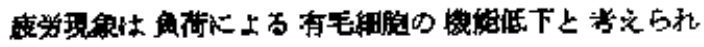

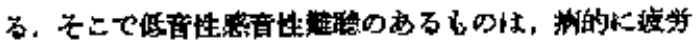

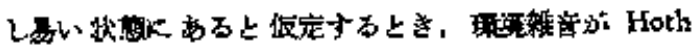

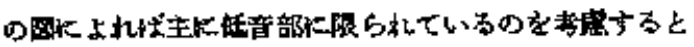

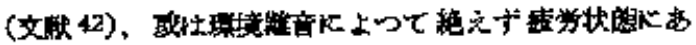
るのではないから磁が成立子る. 若し虔务とい5現

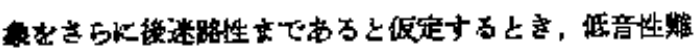

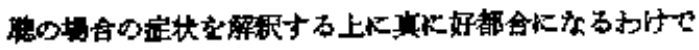

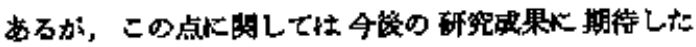
W.

\section{b、紫8 神恇}

Schuknecht

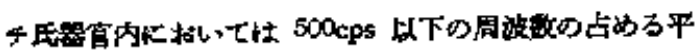

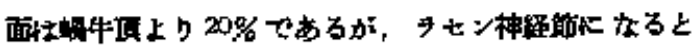

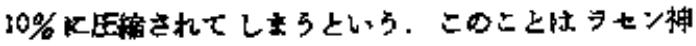

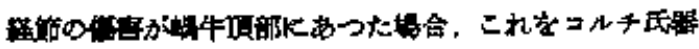

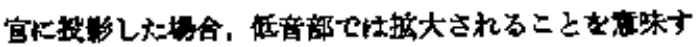

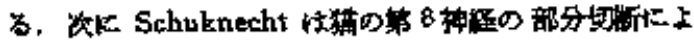

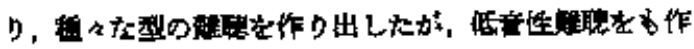

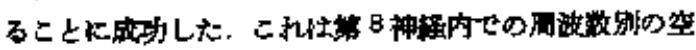

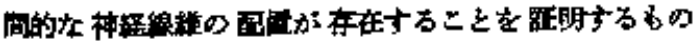

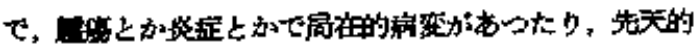

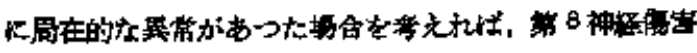

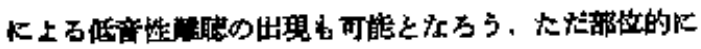

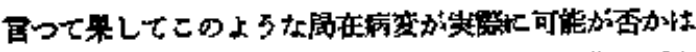

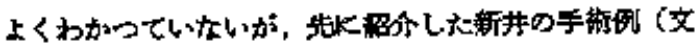

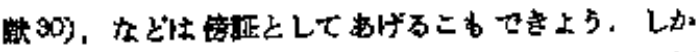

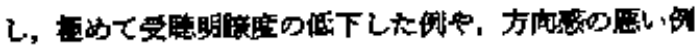

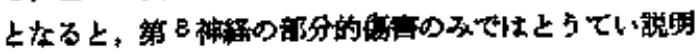

がかが礼くなってしまう。

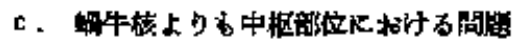

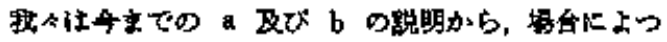

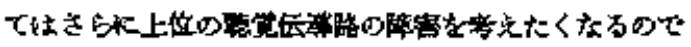

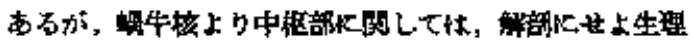

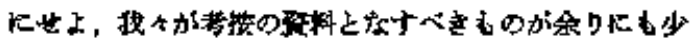

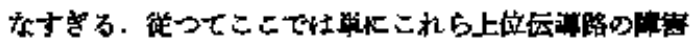

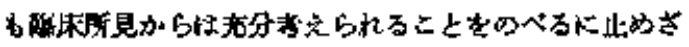

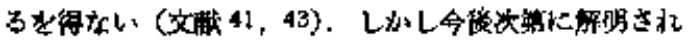

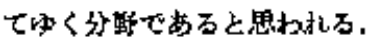

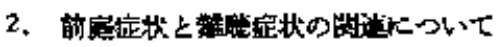

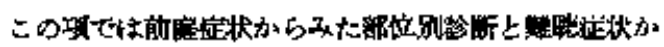

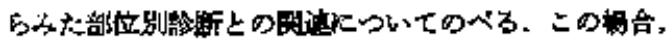

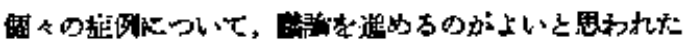
の大. ここ站 4 例孝示寸.

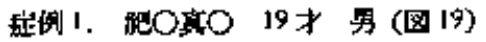

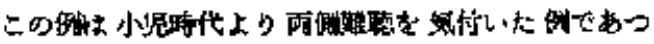

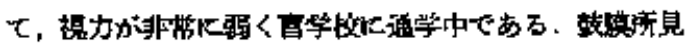

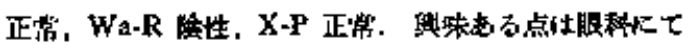

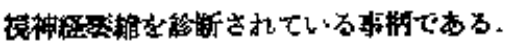

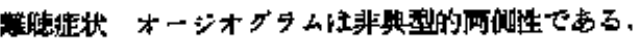

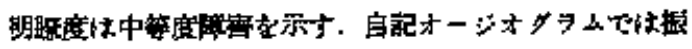

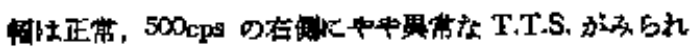

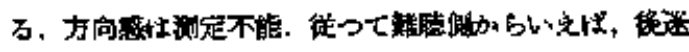

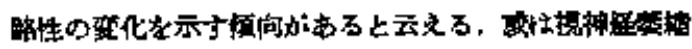

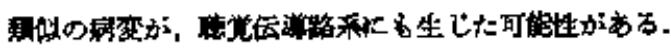

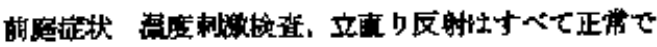

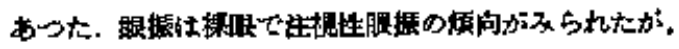

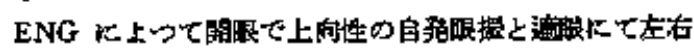

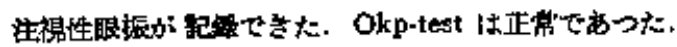

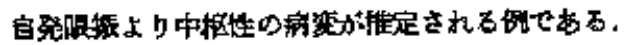

症四 2. 传○榙 15 才男 (图20)

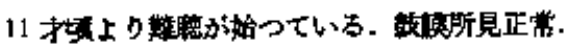

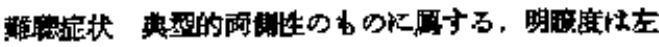

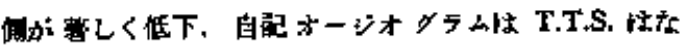

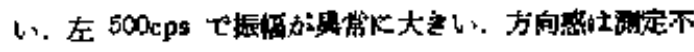

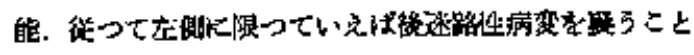

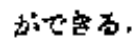

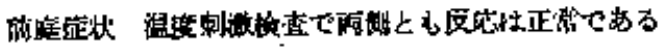

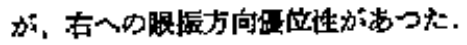

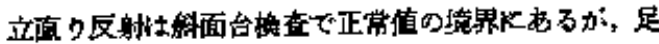

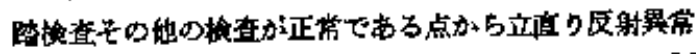

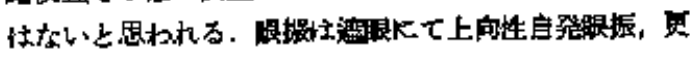




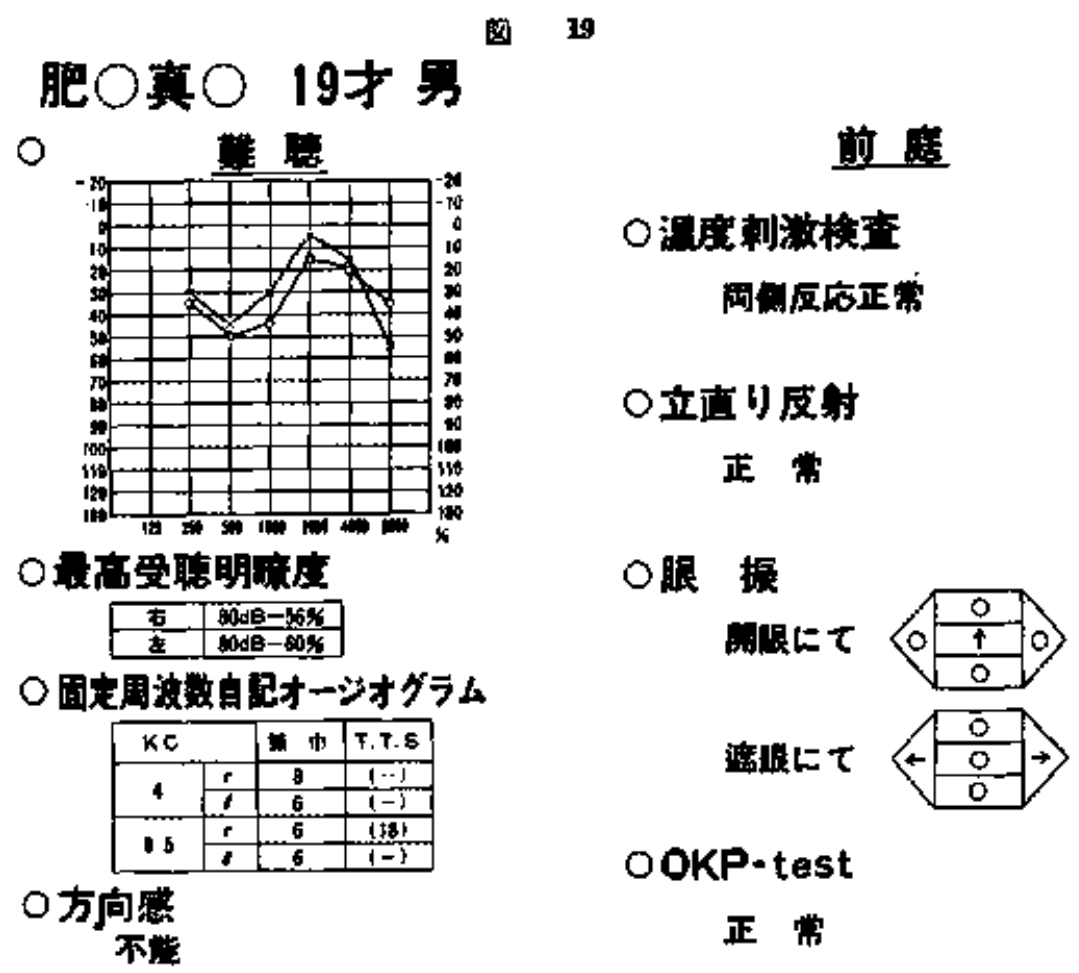

沙 2

传○衡 15才男

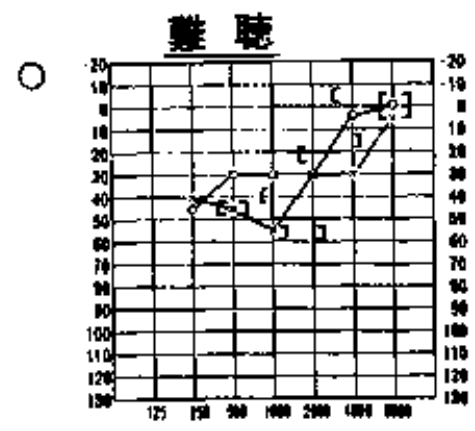
尊应

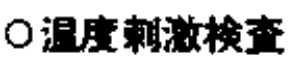
$\mathbf{R}-\mathbf{D P}$
O立国り原期

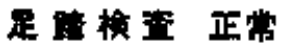

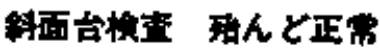
O眼 浱

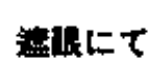

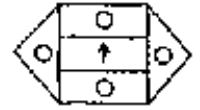
挜服にて

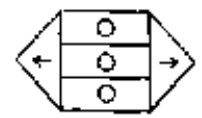
ニの倘なし
OOKP-test

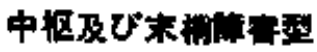

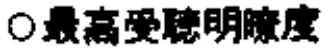

\begin{tabular}{|c|c|}
\hline 5 & $009-70 \%$ \\
\hline$t$ & $0 d 9-20 \%$ \\
\hline
\end{tabular}

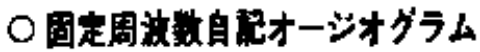

\begin{tabular}{|c|c|c|c|}
\hline $\mathrm{kC}$ & & 해 & t.ts. \\
\hline \multirow{2}{*}{4} & $\bar{r}$ & B & 11 \\
\hline & 4 & 8 & $\{-1$ \\
\hline \multirow{2}{*}{1.5} & $t$ & 15 & $1-7$ \\
\hline & 7 & 24 & {$[\cdot \cdots)$} \\
\hline
\end{tabular}

○方向急 


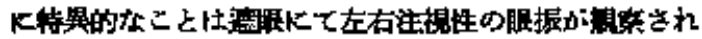

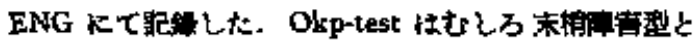
考えられるがしがし，全体的にみると特異大馉振沙ら中

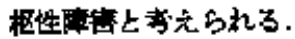

兄にも眼振がる.

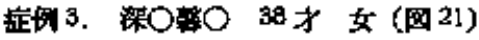

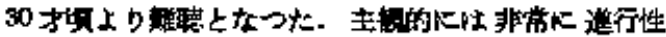

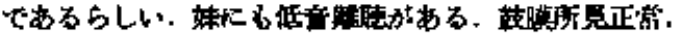

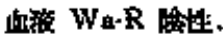

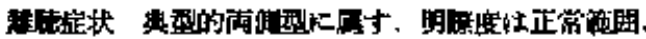

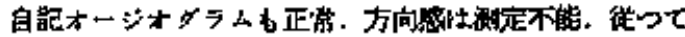

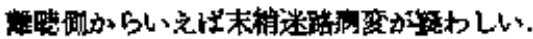

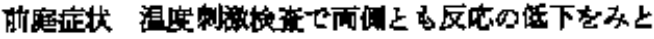

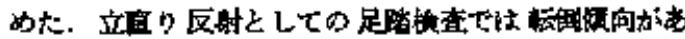

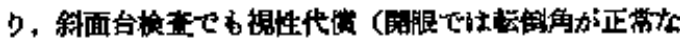

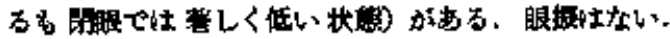

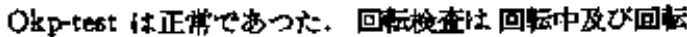

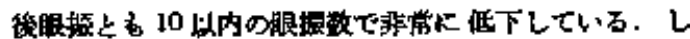
たがつて来梢性の障整と考えられる。

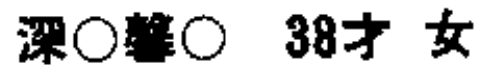

O

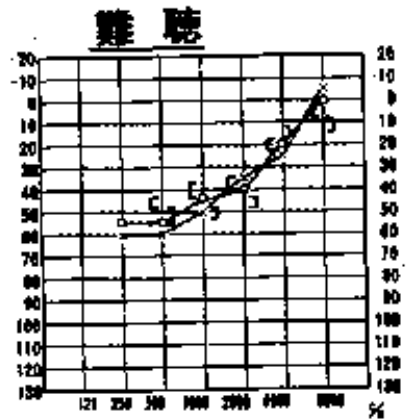

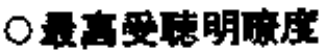

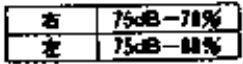

○周定周法数自是オージオグラム

\begin{tabular}{|c|c|c|c|}
\hline $\mathrm{KC}$ & & $\pm \pi$ & T.T.S. \\
\hline 4 & 8 & 2 & $\frac{t-1}{8}$ \\
\hline & $\mathbf{r}$ & 2 & $\frac{8}{i-1}$ \\
\hline 0.3 & $\div$ & 1 & $\frac{i}{i}-1$ \\
\hline
\end{tabular}

\section{○方向感}

不佬
症例 4. 加O韦 18才 女 (图22，23）

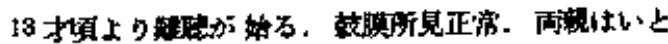

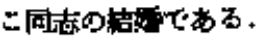

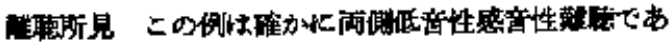

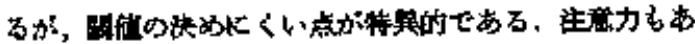

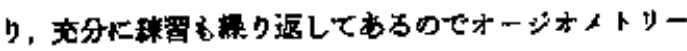

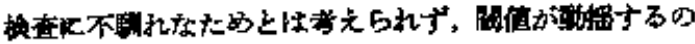

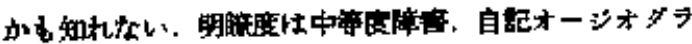

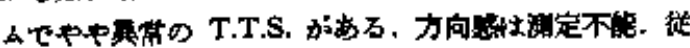

\section{而庭

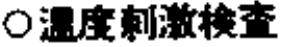

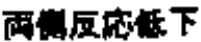 \\ ○立苜り反射

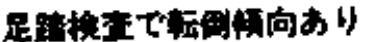

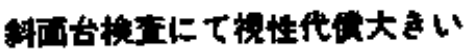

O

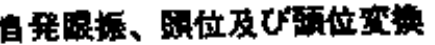
眼振かし

OOKP-test
正 常

O回伝㭲查

反度下

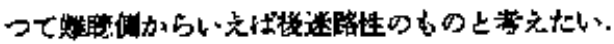

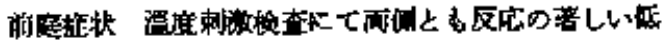

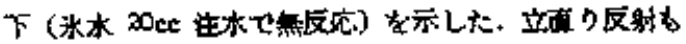

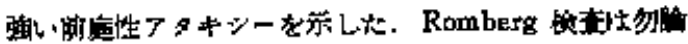

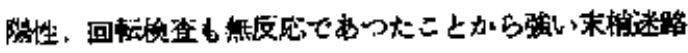

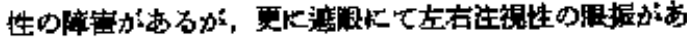

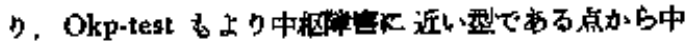

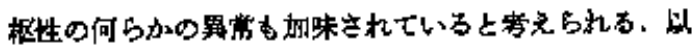

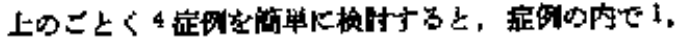




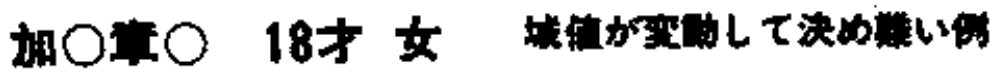
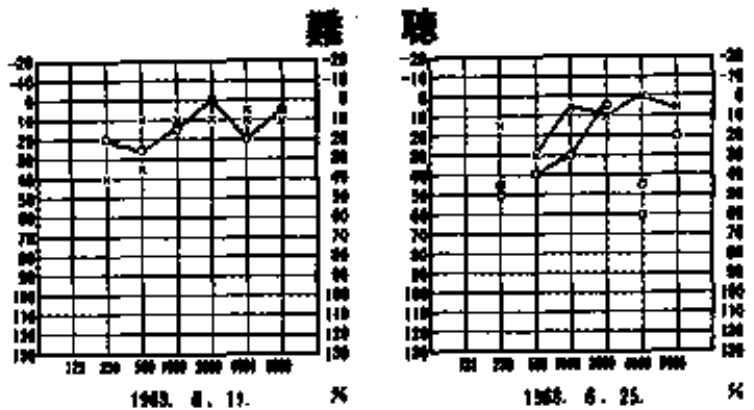

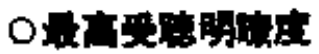
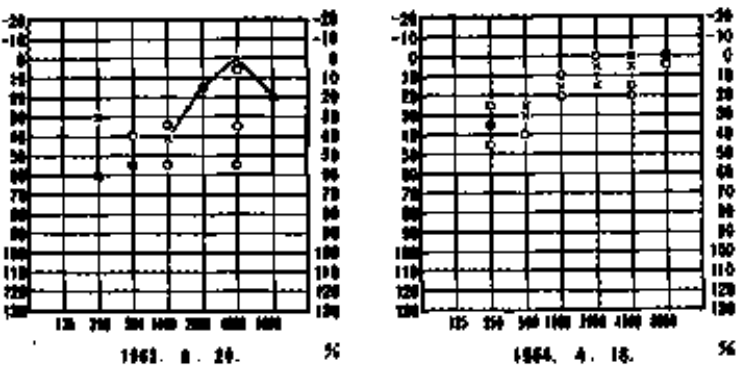

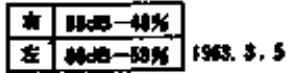

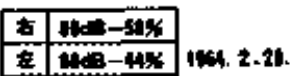

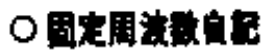

オーシャグラム

图 23

加 $\bigcirc$ 辛 18 才 女

尊糜

○湿度制流湌查

雬哩应低下

水水20c.c で反

\section{○立直り反封}

Romberg test Rt|

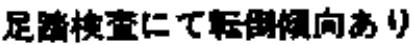

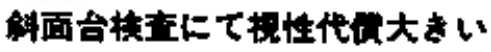

O㤽 振

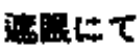

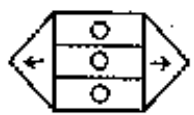

OOKP-test

中枢倍害㓶

O回际模查

级反店

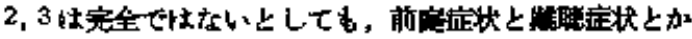

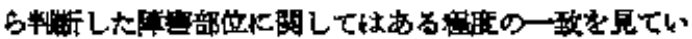

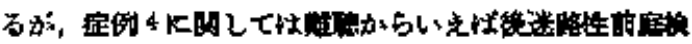

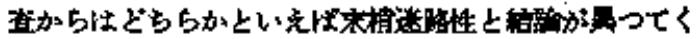

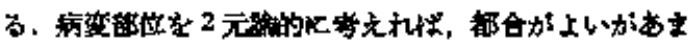

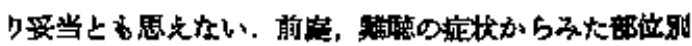

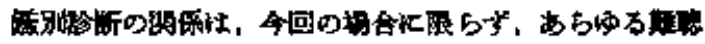

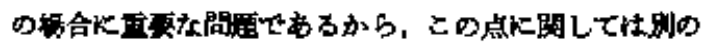

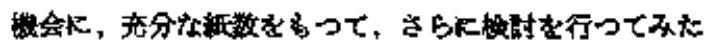
w.

\section{VII. 模}

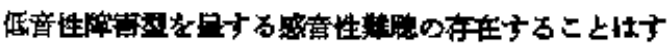

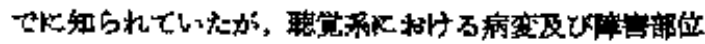

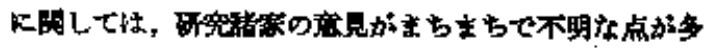

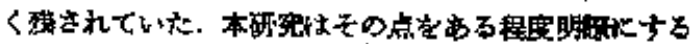

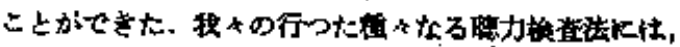

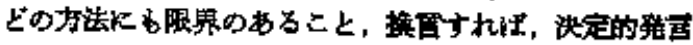
カのあるるのがないこをはつきりとした.

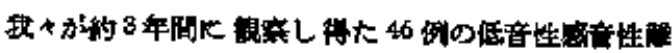

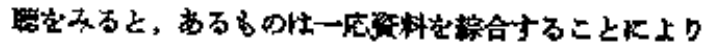

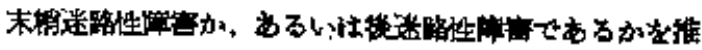

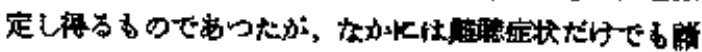




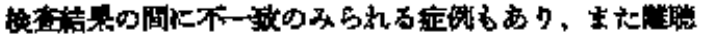

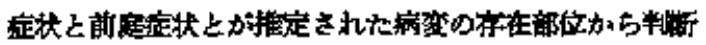

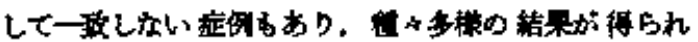
t.

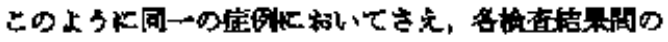

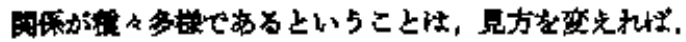

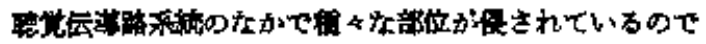

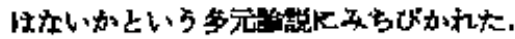

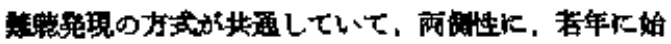

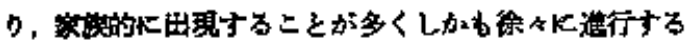

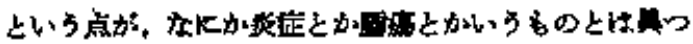

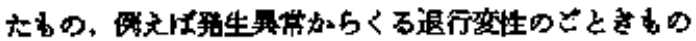

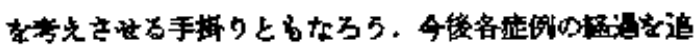

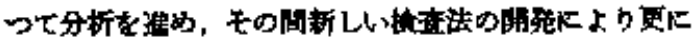

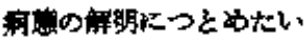

\section{文 冏}

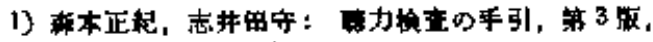

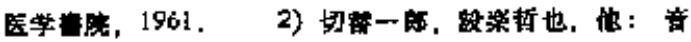

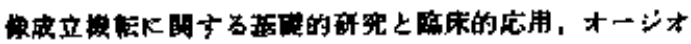
Fシー, 2:1, 1964, Э) Menzel, J.O.: Etkésy audiometry. The Eye, Ear, Nose and Throat Monthly, 42: 77, 1963. 4) Lundorf, $T$. Diagnostic problems concekning acoustic tumors. Acta Otolaryng., Suppl,, 99, 1952. 5) Landes, B.A.. Recruitment measured by automatic andiometry. Arch. Otoleryng., $68 \div 685,1958$.

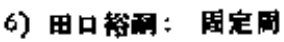

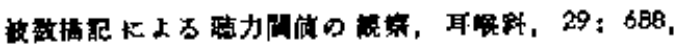
1957. 7) Green, D.S.: The modified tone decay test as a screening procedure for eighth nerve lesions. J.S.H.D. $26: 31$, 1963. 8) Palva, T.

Recrtitment tests at low sensation levels. Laryngoscope, 66: 1519, 1956 ,

9) Fitzgerald, G., and Hallpike, C.S.: Studies in human veatibular function: J. Observations on the directional preponderance of caloric nystograus resulting from cerebral

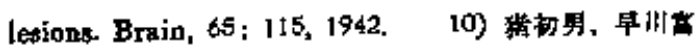

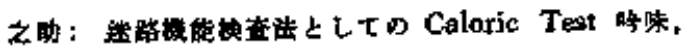

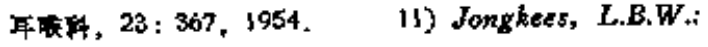
Ueber die Untersuchungsmethoden des Gleichgewichtsorgan. Fortschr. Hals-Nas.-Ohrenheilk., 65,

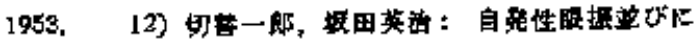

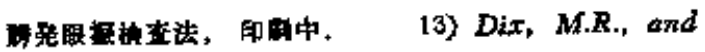
Hallpike, C.S.; The pathology, symptomatology and diagrogis of certsin common diborders of the vestibulat sygtem. Ann. Otol., 61: 987, 1952. 14) Stenger, H.H.: Ueber die Lagerungsnystagmus unter begonderer Berbicksichtigung des gegenläufigen transitorischen Provokationsnystagmus bel Lagewechsel in der Sagittalebene. Arch. Obr, Nas., u. Kehlk.-Heilk. 168: 220，1955，15) 扑识二绝：

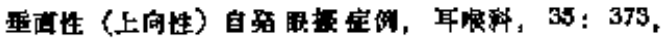
1963. (6) Blomberg, L.H.; The significance of so-called "Endposition nystagmus" and it's relation to nystagmus produced by Evipan. Acte paychiat.,

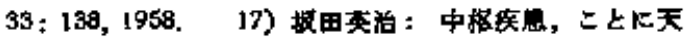

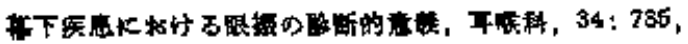

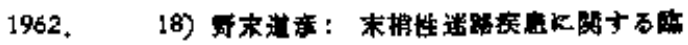
林的研究，耳㙂科，95：901，1963. 19) SvaneKnudsen, V: Sudder "spontaneous" lesion of sural function. Acta Otolarying, 47: 270, 1957. 20) Fürstner, J.K.: Ueber Falle von vertikalem Nystagmus peripheres Ursprungs. Excerpta Med., XI. 14, 1142, 1960, 21) Fernandez, C., et al: Experimental observation on the postural nystagmus in the cat. Ann. Otol., 68; 816, 1959.22 ) Shambaugh, G.F.* Syndrome of diplactsis and nerve deafness for low tones. Arch. Otolaryng., 21 : $694,1935 . \quad 23)$ Williams, H.L.: Ailergy of the inner ear (Menitre's disease) Arch. Otolaryng., 56: 24, 1952. 24) Krassnig-Graz, M.. Das klin. ische Bild der Hirnstammschwerborrigkeit. Arch. Ohr., Ngs., u. Kehlk.-Heilk. 158: 449, $1950 . \quad 25)$ Levalle, $R$. .: The audiogram in cases retinitis pigmentosa. Acta Otolaryng. belg. (cited) 7 : 361 , 1953. 26) Lundborg, $T$.i Nerve deafness for low tones. Acta Otolaryng, 45: 215, 1955, Gravendeel, D.W., and Plomp, R.: Perceptive bass deafness. Acta Otolaryng. $51: 548,1960.28$ ) Cerhart, R.: Atypical audiometric configurations agsociated with otoscrelosis. Anv. Otol, 71: 744.

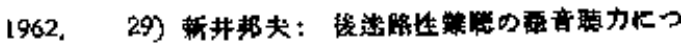

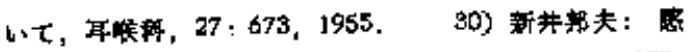

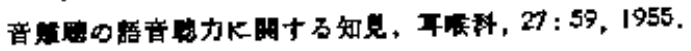

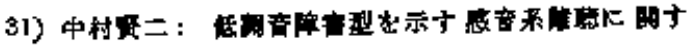

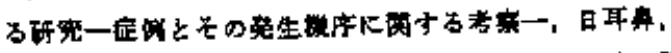

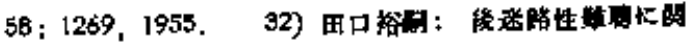




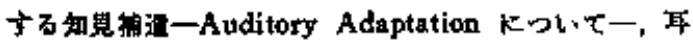

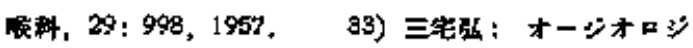

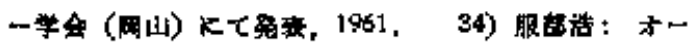

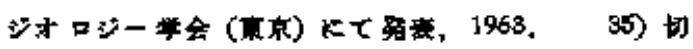

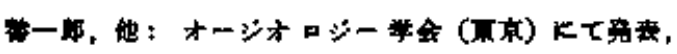
1968, 36) Schukrecht, H.F., and Neff. W.D.; Hearing losses after apical lesion in the cochtea. Acta Otolaryng., 69: 1170, 1952. ST) Sehwknechs, H.F., and Woellner, R.C.: Hearing losses following partial section of the cochlear nerve. Laryngoscope, 69: 441, 1953. 39) Langenbeck, B.: Ueber Basstaubheit. Acta Otolaryng, $57: 257,1963$. 39) Williams, $F$, and Roblee, L.A.' Hereditary nerve denfness in one family. Atch. Otolaryng., 75: 69 , 1963. 40) Schaknechs, H.F.; A clinical study of euditory damage following blows to the head. Aлr. Otol., 59: 391, 1950. 41) Rasmussen, G.L., ed.: Neural mechanisms of the auditory and vestibular syatema. Charles C. Thomas Pub., Springfield, 1960 . 42) Fletcher, H.i Speech and heasing in communication. D. Van Nostrand Company. Princeton, 1961. 43) Galambos, R.; Neura] mechanisms of audition. Physiological Review, 34 : 492, 1954. 44) Gravendeel, D. W.: Perceptive bass deafness, Monograph (Thesis). 45) Neuberger, F: Die Horschwelle. Versuch einer phylogenetischen Interpretation. Arch. Ohr., Nas, u. Kehlk.+Heilk. 166: 140, 1954.4 46) Cawn horne, T.F., and Hinchcliffe, R.; Familial perceptive deafnesses. Pract. Otorbinolaryng, 19: 69, 1957. 47) Ferreri, G., and Coen, R.; Beltrag zur Kenntnis der audiomietrischen Kurven in Form eines V und U. Valsalva, 33 : Suppl, 2, 34, 1957. Zhi. Hals., Nas., u. Ohrenheilk, 59 : 242, 1957/58... 48) Fisch, L.: The etiology of congenital deafness and andiometric patterns J. Laryng., $69: 479,1955$. 49) Marsensson, B.: Dominant hereditary nerve deafness. Acta Otolaryng, 52; 270, 1960. Franr, H.: HHufigkeit und Ursache der U-formig verlaufenden audiometrischen Horschwellenkurve.

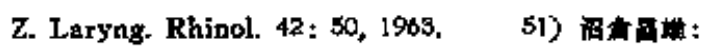

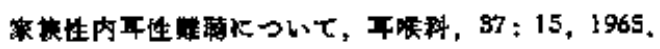

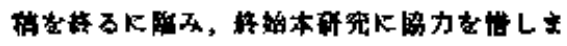

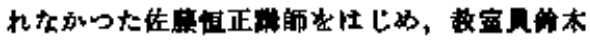

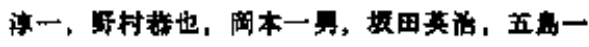

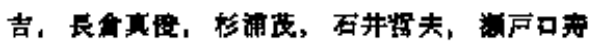

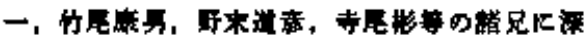

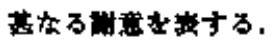

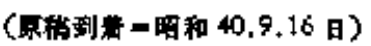

